\title{
The Current Status of Heterogeneous Palladium Catalysed Heck and Suzuki Cross-Coupling Reactions
}

\author{
Philani P. Mpungose ${ }^{1}$ (), Zanele P. Vundla ${ }^{1}$, Glenn E. M. Maguire ${ }^{2}$ and Holger B. Friedrich ${ }^{1, *}$ \\ 1 Catalysis Research Group, School of Chemistry and Physics, University of KwaZulu-Natal, Westville \\ Campus, Durban 4000, South Africa; 207506038@stu.ukzn.ac.za (P.P.M.); sjaejj@gmail.com (Z.P.V.) \\ 2 School of Chemistry and Physics, University of KwaZulu-Natal, Varsity Drive, Durban 4001, South Africa; \\ maguireg@ukzn.ac.za \\ * Correspondence: friedric@ukzn.ac.za; Tel.: +27-31-2603107; Fax: +27-31-2603091
}

Received: 31 May 2018; Accepted: 23 June 2018; Published: 10 July 2018

\begin{abstract}
In the last 30 years, $\mathrm{C}-\mathrm{C}$ cross coupling reactions have become a reliable technique in organic synthesis due their versatility and efficiency. While drawbacks have been experienced on an industrial scale with the use of homogenous systems, many attempts have been made to facilitate a heterogeneous renaissance. Thus, this review gives an overview of the current status of the use of heterogeneous catalysts particularly in Suzuki and Heck reactions. Most recent developments focus on palladium immobilised or supported on various classes of supports, thus this review highlights and discuss contributions of the last decade.
\end{abstract}

Keywords: C-C cross coupling; Heck cross-coupling; Suzuki cross-coupling; heterogeneous palladium catalysis

\section{Introduction}

The importance of carbon-carbon bond forming reactions is well documented in literature [1-3]. The industrial importance of Suzuki and Heck cross-coupling reactions along with numerous others in this general field has sparked great interest in $\mathrm{C}-\mathrm{C}$ bond formation reactions. In addition, the lack of a universal set of reaction conditions for every catalyst system and the drawbacks of industrially employed catalyst systems continue to fuel this interest. Heck and Suzuki reactions are typically catalysed by palladium based homogenous systems that have illustrated high turnover frequency (TOFs). These homogeneous catalysts require the use of ligands (phosphine or $N$-heterocyclic) to form active catalysts. As a result, separation of these catalysts (the ligand, the Pd metal or the complex) from the reaction media has presented the greatest challenge in this field. Consequently, the catalyst gets incorporated into the final product, resulting in loss of catalyst and a devalued product especially since these reactions are at the forefront of the production in the pharmaceutical industry. Successful separation of these homogeneous catalysts from the product solution requires the use of expensive nanofiltration membranes or an extensive (and usually destructive) column chromatography separation. Table 1 summarises the maximum limits of residual metal catalysts acceptable in the pharmaceutical industry.

These low allowed concentrations have prompted the development of recoverable and reuseable catalyst systems to decrease product contamination and alleviate the loss of catalyst. Many attempts have been made over the years to heterogenise homogeneous systems and to develop heterogeneous systems to displace homogenous systems and this review aims at highlighting recent contributions of the last decade at achieving this. 
Table 1. Maximum acceptable concentration limits for the residues of metal catalysts that can be present in pharmaceutical products [4].

\begin{tabular}{ccc}
\hline \multirow{2}{*}{ Metal } & \multicolumn{2}{c}{ Concentration (ppm) } \\
\cline { 2 - 3 } & Oral & Parenteral \\
\hline $\mathrm{Pd}, \mathrm{Pt}, \mathrm{Ir}, \mathrm{Rh}, \mathrm{Ru}, \mathrm{Os}$ & 5 & 0.5 \\
$\mathrm{Mo}, \mathrm{V}, \mathrm{Ni}, \mathrm{Cr}$ & 10 & 1.0 \\
$\mathrm{Cu}, \mathrm{Mn}$ & 15 & 1.5 \\
$\mathrm{Zn}, \mathrm{Fe}$ & 20 & 2.0 \\
\hline
\end{tabular}

The main challenge in the development of heterogeneous catalytic systems for $\mathrm{C}-\mathrm{C}$ cross-coupling reactions has been in establishing the nature of the active catalyst species. While literature on homogeneous systems is well developed with the mechanism well understood, the contrary is observed for heterogeneous catalysts. The true nature of the active catalyst when a palladium containing solid material is employed as a catalyst is still a highly debated issue in the field of cross-coupling reactions [5]. In most research papers, the "true nature" of the active form of palladium is ambiguous; claims exist in the literature supporting both soluble molecular and nanoparticle catalysts, as well as truly heterogeneous insoluble Pd catalysts [5-7]. More specifically, the question is whether the oxidative addition of the aryl halide ( $\mathrm{Ar}-\mathrm{X}$ ) occurs on the surface of the solid catalyst (heterogeneous catalysis) or on leached metal atoms (homogeneous catalysis). The literature is currently divided on this matter; some researchers recognise the solid pre-catalyst as a "reservoir" of soluble catalytically active palladium species [4,8-10]. Others claim to have developed truly heterogeneous systems, with catalysis taking place on the surface of the solid palladium based heterogeneous catalyst [11,12].

Common heterogeneous cross-coupling catalysts mainly differ in: (i) chemical nature (organic, inorganic, or hybrid organic-inorganic) of the solid matrix entrapping the Pd catalyst and (ii) the nature of the catalyst attachment (chemical or physical entrapment) [13]. There are also examples of efficient catalysts for cross-coupling reactions based on colloidal palladium particles. The usefulness of the developed catalytic system is usually determined by its activity, selectivity and the life-time of the catalyst [14]. The catalytic activity is essentially a measure of percentage of reactants that are converted to product(s); while the catalytic selectivity is a measure of the percentage of the reactants that are converted to useful or desired product(s). The life-time of a catalyst is the time that the catalyst will maintain the required level of activity and selectivity [14]. The life-time of the catalyst can also be estimated by the number of times it can be recovered and reused. Lastly, the efficiency of a catalytic process is measured in turnover number (TON) and turnover frequency (TOF).

In the following discussion, the catalytic properties discussed above will be used to determine the efficiency of the selected examples of most common palladium catalyzed heterogeneous catalytic systems for Heck and Suzuki cross-coupling reactions. The aim of the discussion is not to be exhaustive but rather to report on recent and noteworthy research progress aimed at developing heterogeneous palladium based catalytic systems.

\section{2. "Naked" Palladium Nanoparticles as Pre-Catalysts}

Palladium nanoparticles have become one of the most interesting forms of heterogeneous catalysts because of their size- and shape-dependence, as well as their efficient catalytic activities in cross-coupling reactions $[13,15]$. The "naked" palladium nanoparticles are the simplest form of heterogeneous catalyst for $\mathrm{C}-\mathrm{C}$ cross-coupling reactions. However, their use has been limited by the lack of efficient separation procedures; available separation techniques such as filtration and centrifugation are not very effective in achieving complete recovery of the nanoparticles. Additionally, nanoparticles are susceptible to oxidation, resulting in complicated work up procedures in the attempt to avoid deactivation. Furthermore, nanoparticles are also prone to agglomeration or sintering upon heating, leading to formation of insoluble non-catalytic palladium black [13]. Scheme 1 shows that a palladium metal aggregate can serve as catalytically active palladium reservoir. In situ, the palladium 
metal aggregates produce kinetically stable palladium nanoparticles that facilitate the heterogeneous catalytic cycle. However, single palladium atoms usually leach out from the surface of the palladium nanoparticle and participate in the homogeneous catalytic cycle.

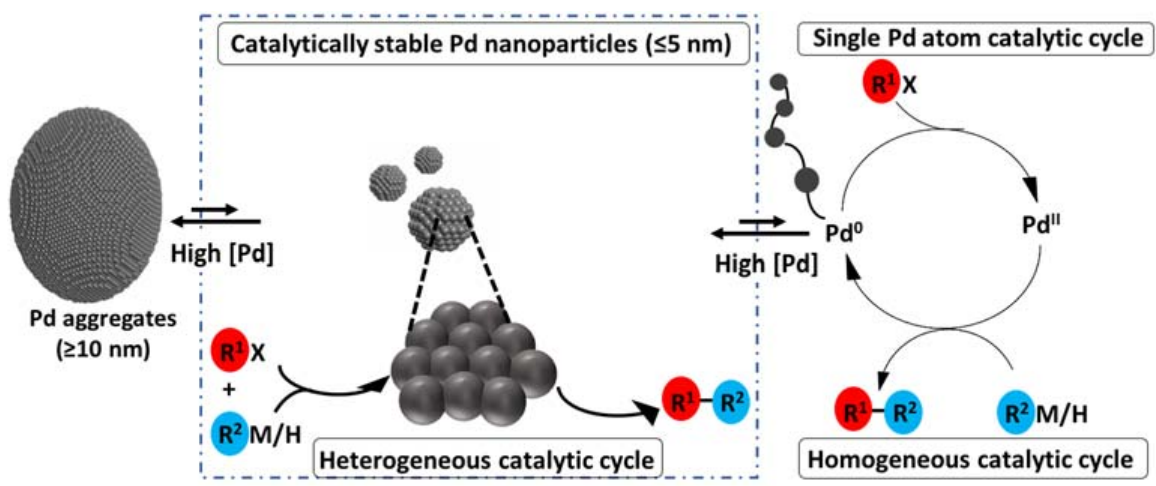

Scheme 1. Possible reaction pathways operating in Pd nanoparticle catalysed Suzuki and Heck cross-couplings [12] (Adapted with permission from American Chemical Society).

Alternatively, supported palladium nanoparticles as catalyst for $\mathrm{C}-\mathrm{C}$ cross-coupling reactions are being developed. Most often, palladium nanoparticle become less catalytically active upon immobilisation on a solid support. Therefore, an improved catalytic system with desirable aspects of both systems (high activity and easy recovery) is needed. It is envisaged that better understanding of the reactivity of palladium nanoparticle can lead to the design of more efficient heterogeneous catalyst for $\mathrm{C}-\mathrm{C}$ cross-coupling reactions.

\section{Palladium Nanoparticles on Carbonaceous Supports}

Palladium supported on carbonaceous supports has been widely applied in C-C cross-coupling reactions (Scheme 2) [16-18]. Amongst these, palladium on activated carbon (Pd/C) is by far the most frequently used catalyst in heterogeneous Pd-catalyzed coupling reactions. This is because of its efficiency and commercial availability [16-18]. It can be purchased in various quantities with a palladium content ranging from 1-20\%. In addition, charcoal as a solid support ensures a higher surface area compared to the corresponding alumina and silica supported catalysts [18]. Palladium on activated carbon is reported to be stable in air and water, acids and bases, and it often doesn't require reactions to be performed under an inert atmosphere [18,19]. As a result, Pd/C catalyzed Heck and Suzuki cross-coupling reactions have been performed under a variety of reactions conditions, including in organic media [20-23], aqueous media [24-26], and under microwave conditions [27-31]. Generally, the Pd/C catalyst can convert a large variety of substrates with good to excellent yields, and it is recoverable and recyclable over many cycles [16-18].

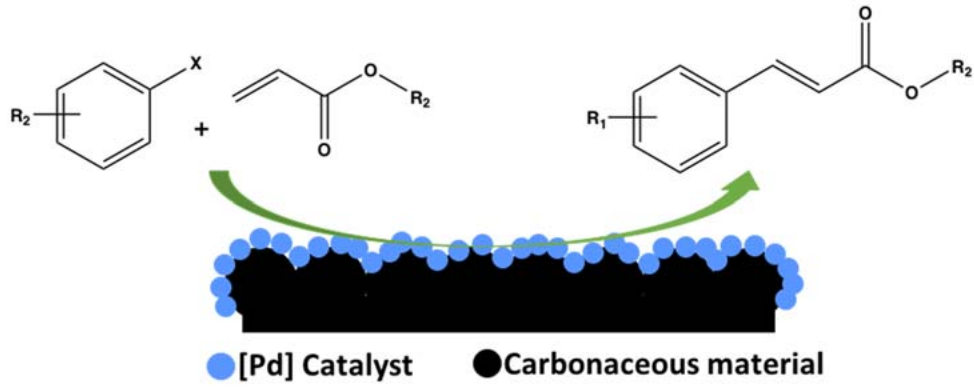

Scheme 2. Schematic illustration of palladium nanoparticles supported on carbonaceous material as efficient catalyst for C-C cross-coupling reactions [32] (Adapted with permission from John Wiley and Sons). 
Jadhav et al. recently (2016) developed a greener, cost effective and operationally convenient $\mathrm{Pd} / \mathrm{C}$ based catalytic system for Suzuki and Heck cross-coupling reactions [33]. In their setup, the $\mathrm{Pd} / \mathrm{C}$ catalyst was dispersed in an aqueous hydrotropic medium (sodium xylene sulphonate solution) that had surfactant-like properties and thus stabilised the $\mathrm{Pd} / \mathrm{C}$ catalyst (Figure 1). The hydrotropism allows for easy solubility of several types of organic functionalities in water, without the need for toxic and volatile organic co-solvent. In addition, good to excellent yields of the desired product were obtained and the catalytic system was recycled three times without any significant loss in activity. Lastly, they reported that the palladium metal was "not leached" out into the product solution. Hence, this system is highly desirable from economical as well as environmental points of view.

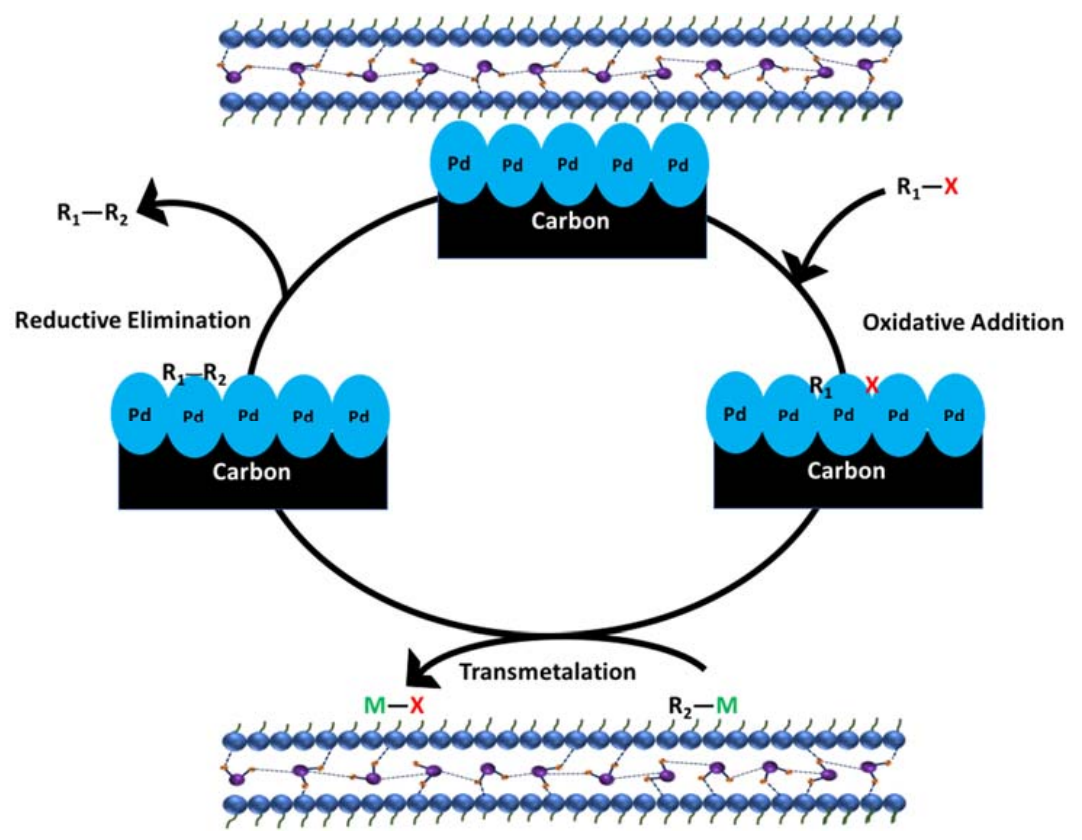

Figure 1. Plausible mechanism of the $\mathrm{C}-\mathrm{C}$ bond forming reactions in the presence of a hydrotrope (sodium xylene sulphonate solution) [33] (Adapted with permission from The Royal Society of Chemistry).

Carbon nanotubes (CNTs) have emerged as highly efficient supports for palladium and they have been extensively used as alternatives to activated carbon supports $[12,32,34,35]$. The CNTs can be evenly distributed in solution due to their small size, thus increasing interaction between the reactants and the catalyst. In most cases, the activity of CNTs in C-C cross-coupling reactions depends on their preparation method [35]. In a recent review, by Labulo et al., a wide range of surface functionalization techniques for carbon nanotubes that improve their properties as catalyst supports was reported [34]. The resulting CNTs catalysts displayed superior catalytic performance and better recyclability in C-C cross-coupling reactions. Scheme 3 shows the graphical representation of surface functionalization and palladium nanoparticle loading onto carbon nanotubes.

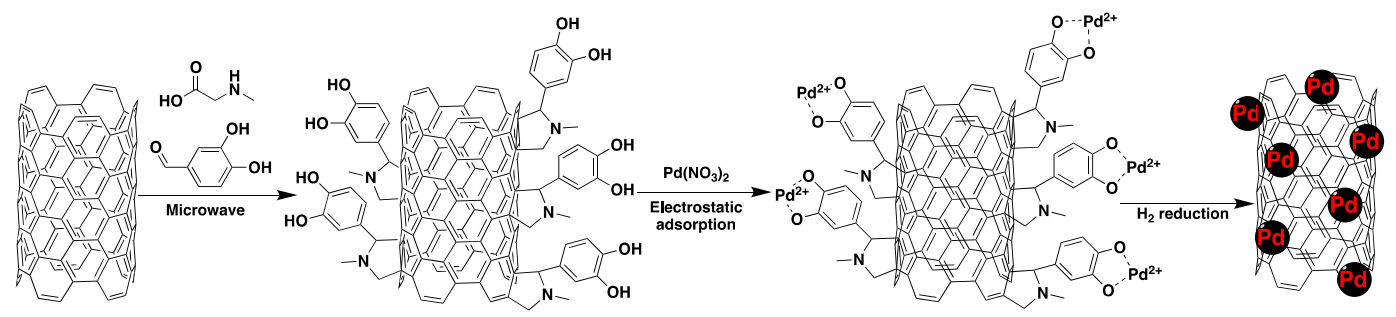

Scheme 3. Graphical representation of Pd nanoparticles supported on carbon nanotubes [34] (Adapted with permission from Springer Nature). 
Lakshminarayana et al. [32] extended the study by investigating the influence of various carbonaceous materials as supports in $\mathrm{C}-\mathrm{C}$ cross-coupling reactions. They prepared and studied palladium oxide $(\mathrm{PdO})$ nanoparticles impregnated on nanocarbon supports, such as single walled carbon nanotubes (SWCNT), multiwalled carbon nanotubes (MWCNT), carbon nanofiber (CNF), graphene oxide (GO), and reduced graphene oxide (RGO) [32]. The prepared catalysts were characterized fully and then explored in Heck cross-coupling reactions to assess their catalytic activity. Graphene oxide (GO) was found to be the best support for PdO (Table 2). The enhanced catalytic activity of $\mathrm{PdO} / \mathrm{GO}$ was believed to be due to the combined effect of a high degree of surface-bound oxygenated moieties, high surface area, electron conductivity and the mesoporous nature of graphene oxide.

Table 2. Performance of PdO supported carbon materials in the Heck coupling reaction [32] (Adapted with permission from John Wiley and Sons).

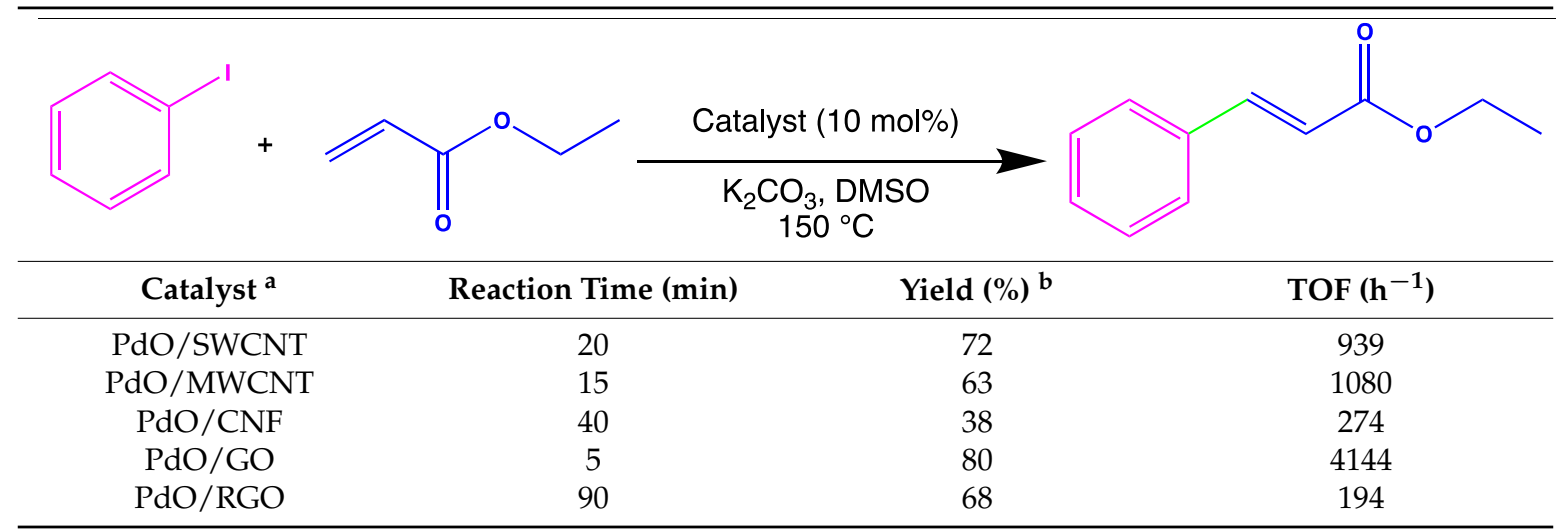

${ }^{a}$ Reaction Conditions: Iodobenzene $(0.25 \mathrm{mmol})$, ethyl acrylate $(0.5 \mathrm{mmol}), \mathrm{PdO} /$ support $(10 \mathrm{~mol} \%), \mathrm{K}_{2} \mathrm{CO}_{3}$ (0.5 mmol), DMSO (dimethylsuloxide) $(1 \mathrm{~mL})$ at $150{ }^{\circ} \mathrm{C} .{ }^{\mathrm{b}} \mathrm{GC}$ yields.

\section{Palladium Nanoparticles on Metal Oxide Supports}

A significant number of researchers have devoted themselves to finding a new and a more efficient $\mathrm{Pd} / \mathrm{M}_{\mathrm{x}} \mathrm{O}_{\mathrm{y}}$ based heterogeneous catalyst for $\mathrm{C}-\mathrm{C}$ cross-coupling reactions [36,37]. In this direction, Köhler and co-workers prepared and comparatively studied the catalytic activity of $\mathrm{Pd} / \mathrm{Al}_{2} \mathrm{O}_{3}, \mathrm{Pd} / \mathrm{TiO}_{2}, \mathrm{Pd} / \mathrm{NaY}$, and $\mathrm{Pd} / \mathrm{CeO}_{2}$ [38]. The catalysts were able to efficiently catalyse Suzuki cross-coupling reactions and the obtained TOFs for each catalyst were: $\mathrm{Pd} / \mathrm{Al}_{2} \mathrm{O}_{3}=9600 \mathrm{~h}^{-1}$, $\mathrm{Pd} / \mathrm{TiO}_{2}=9700 \mathrm{~h}^{-1}, \mathrm{Pd} / \mathrm{NaY}=4100$, and $\mathrm{Pd} / \mathrm{CeO}_{2}=4100 \mathrm{~h}^{-1}$. The Pd $/ \mathrm{Al}_{2} \mathrm{O}_{3}$ and $\mathrm{Pd} / \mathrm{TiO}_{2}$ catalysts showed very similar and high catalytic activities, while the activities of $\mathrm{Pd} / \mathrm{NaY}$ and $\mathrm{Pd} / \mathrm{CeO}_{2}$ were much lower. The TOF values of $\mathrm{Pd} / \mathrm{NaY}$ and $\mathrm{Pd} / \mathrm{CeO}_{2}$ catalysts are almost half of those obtained with $\mathrm{Pd} / \mathrm{Al}_{2} \mathrm{O}_{3}$ and $\mathrm{Pd} / \mathrm{TiO}_{2}$. These results clearly suggest that the nature of the support has a great influence on the activity of the catalyst.

In addition, Köhler et al. stated that the Pd concentration in solution during the reaction correlated clearly with the progress of the reaction (Figure 2). Thus, this clearly suggests that the dissolved molecular palladium represents the "true" catalytically active species, and the prepared $\mathrm{Pd} / \mathrm{M}_{\mathrm{x}} \mathrm{O}_{\mathrm{y}}$ solids are simply precursors to the "true catalyst". Furthermore, they found that the dissolved "Pd is deposited back" onto the support at the end of the reaction. This phenomenon is commonly referred to as the palladium "release-capture or dissolution-redeposition" mechanism [39]. 


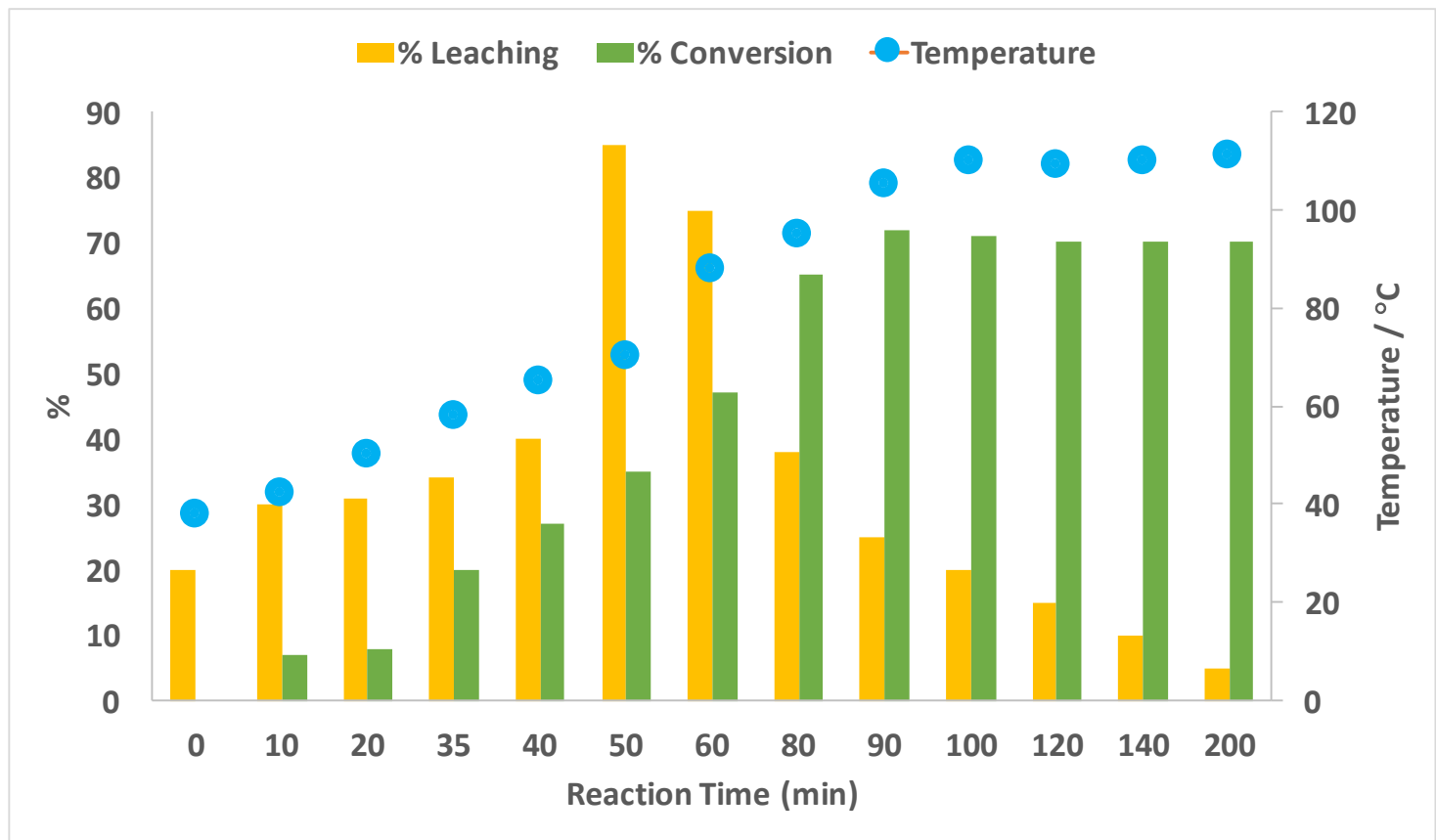

Figure 2. Time-dependent correlation of palladium leaching with the progress of the reaction [38] (Adapted with permission from John Wiley and Sons).

In 2013, Amoroso et al. [10] extended the study of Köhler and co-workers [38] to examine the catalytic activity of $\mathrm{Pd} / \mathrm{M}_{\mathrm{x}} \mathrm{O}_{\mathrm{y}}$ type catalysts in more detail. More specifically, they wanted to investigate the influence of the "point of zero charge" on the catalytic activity of the $\mathrm{Pd} / \mathrm{M}_{\mathrm{x}} \mathrm{O}_{\mathrm{y}}$ type catalysts. The point of zero charge (PZC) is commonly used in surface science to determine the ability of a given solid material to adsorb ions. This concept describes the condition when the electrical charge density on a surface of a solid is zero [40]. Generally, the PZC is represented as the pH value at which a solid submerged in an electrolyte exhibits zero net electrical charge on the surface [40,41]. A given metal oxide $\left(\mathrm{M}_{\mathrm{x}} \mathrm{O}_{\mathrm{y}}\right)$ surface will have a "positive charge" at solution $\mathrm{pH}$ values less than the PZC value and thus be a surface on which anions may adsorb. On the other hand, the metal oxide surface will have a negative charge at solution $\mathrm{pH}$ values greater than the PZC value and thus be a surface on which cations may adsorb $[40,41]$. The later statement is more relevant to the current discussion since the $\mathrm{pH}$ of the reaction mixture in most cross-coupling reactions is around 10, thus it is above the PZC values of the investigated metal oxide supports (Figure 3). This allows one to investigate the degree of adhesion of palladium onto the support, which in turn speaks to the observed catalytic activity and the degree of palladium leaching.
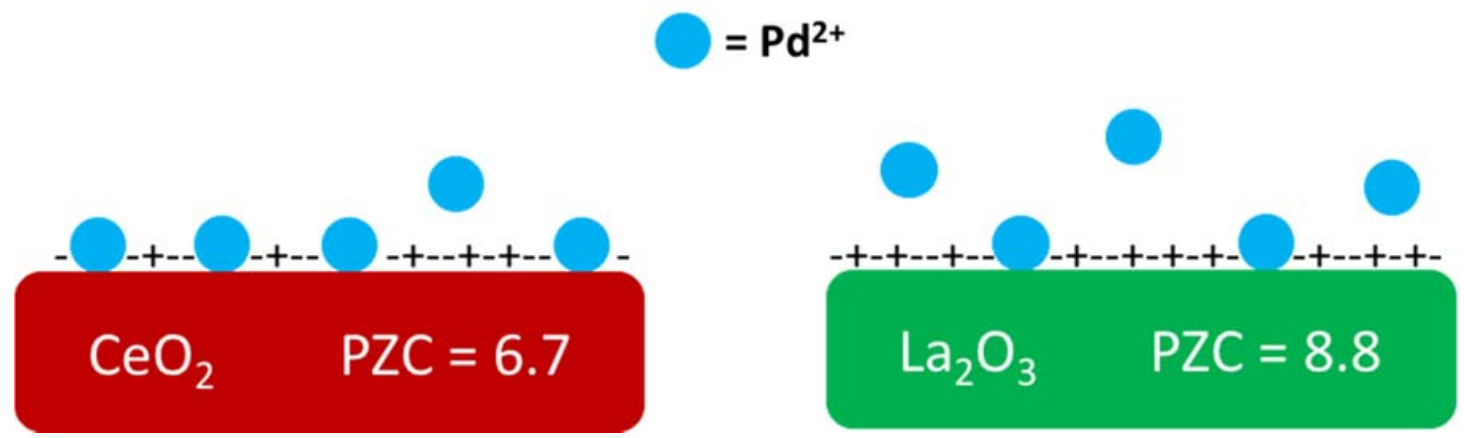

Figure 3. Representation of adhesion and release of $\mathrm{Pd}^{2+}$ from $\mathrm{CeO}_{2}$ and $\mathrm{La}_{2} \mathrm{O}_{3}$ surfaces under catalytic conditions ( $\mathrm{pH} \sim 10.5$ ) [42] (Adapted with permission from The Royal Society of Chemistry). 
Hence, Amoroso et al. [10] used the PZC values of each support to investigate the role it plays in the adhesion of the palladium nanoparticle onto the surface of the support (Figure 3). Thus, they prepared and investigated the catalytic activity of $\mathrm{Pd} / \mathrm{La}_{2} \mathrm{O}_{3}, \mathrm{Pd} / \mathrm{Pr}_{6} \mathrm{O}_{11}, \mathrm{Pd} / \mathrm{Gd}_{2} \mathrm{O}_{3}, \mathrm{Pd} / \mathrm{Sm}_{2} \mathrm{O}_{3}$, and $\mathrm{Pd} / \mathrm{CeO}_{2}$ catalysts. The physicochemical properties of these materials are tabulated in Table 3 . The study revealed that under basic reaction conditions ( $\mathrm{pH} \sim 10.5)$, the surfaces of metal oxides with high PZC values are less negatively charged than the surfaces of metal oxides with low PZC values. Thus, the $\mathrm{La}_{2} \mathrm{O}_{3}$ support has the lowest density of negatively charged sites on the surface since it has the highest $\mathrm{PZC}$ value. Hence, the higher reactivity of $\mathrm{Pd} / \mathrm{La}_{2} \mathrm{O}_{3}$ is correlated to a marked degree of $\mathrm{Pd}^{2+}$ leaching from the surface of $\mathrm{La}_{2} \mathrm{O}_{3}$, favoured by its less negatively charged surface. On the contrary, the lowest activity observed with $\mathrm{Pd} / \mathrm{CeO}_{2}$ is correlated to the higher degree of negatively charged surface that helps in keeping $\mathrm{Pd}^{2+}$ ions anchored onto the support (Figure 3).

Table 3. The physicochemical properties of the synthesised $\mathrm{Pd} / \mathrm{M}_{\mathrm{x}} \mathrm{O}_{\mathrm{y}}$ based catalysts and their catalytic activity results [10] (Adapted with permission from Springer Nature).

\begin{tabular}{|c|c|c|c|c|c|c|}
\hline & + & & $\begin{array}{r}\mathrm{Pd} / \mathrm{M}_{\mathrm{x}} \mathrm{O}_{\mathrm{y}}(0 \\
\text { Ethanol/w } \\
\mathrm{K}_{2} \mathrm{CO}_{3},\end{array}$ & $\frac{\text { ol\%) }}{3: 1)}$ & & \\
\hline $\begin{array}{l}\text { Compound } \\
\left(\mathrm{Pd} / \mathrm{M}_{\mathrm{x}} \mathrm{O}_{\mathrm{y}}\right)^{\mathrm{a}}\end{array}$ & $\begin{array}{l}\text { Pd Loading } \\
(w t \%)\end{array}$ & $\begin{array}{c}\text { Surface } \\
\text { Area }\left(\mathrm{m}^{2} / \mathrm{g}\right)\end{array}$ & $\begin{array}{l}\text { Pore Volume } \\
\quad\left(\mathrm{cm}^{3} / \mathrm{g}\right)\end{array}$ & $\begin{array}{l}\mathrm{PZC} \\
(\mathrm{pH})\end{array}$ & Time (min) & TOF $\left(h^{-1}\right)$ \\
\hline $\mathrm{Pd} / \mathrm{La}_{2} \mathrm{O}_{3}$ & 1.76 & 16.6 & 0.24 & 8.8 & 13 & 9130 \\
\hline $\mathrm{Pd} / \mathrm{CeO}_{2}$ & 1.93 & 31.5 & 0.18 & 6.7 & 260 & 450 \\
\hline $\mathrm{Pd} / \mathrm{Pr}_{6} \mathrm{O}_{11}$ & 1.93 & 22.4 & 0.36 & 7.8 & 17 & 6980 \\
\hline $\mathrm{Pd} / \mathrm{Sm}_{2} \mathrm{O}_{3}$ & 1.84 & 11.9 & 0.21 & 7.4 & 21 & 5650 \\
\hline $\mathrm{Pd} / \mathrm{Gd}_{2} \mathrm{O}_{3}$ & 1.99 & 10.2 & 0.09 & 7.5 & 20 & 5940 \\
\hline
\end{tabular}

${ }^{a}$ Reaction conditions: 1-bromo-4-nitrobenzene $(0.5 \mathrm{mmol})$, 4-methylphenylboronic acid $(0.6 \mathrm{mmol}), \mathrm{K}_{2} \mathrm{CO}_{3}$ $(0.6 \mathrm{mmol})$, catalyst, $1.5 \mathrm{~mL}$ ethanol, $0.5 \mathrm{~mL}$ water, temperature $=25^{\circ} \mathrm{C}$.

Figure 4 further shows that there is a linear correlation between the yield of the coupling product and the PZC $\left(\left[\mathrm{H}_{3} \mathrm{O}^{+}\right]=10^{-\mathrm{PZC}}\right)$ value of the metal oxide support. Thus, the observed reactivity trend over the $\mathrm{M}_{\mathrm{x}} \mathrm{O}_{\mathrm{y}}$ support is related to the tendency of each $\mathrm{Pd} / \mathrm{M}_{\mathrm{x}} \mathrm{O}_{\mathrm{y}}$ system to deliver different amounts of palladium into the solution. In summary, the above discussion shows that there is a close relation between the "surface charge" (correlated to the PZC value) and the extent of palladium leaching at the $\mathrm{pH}$ of catalysis (determined by reaction conditions). Thus, the more positively charged is the surface (this is the case of $\mathrm{Pd} / \mathrm{La}_{2} \mathrm{O}_{3}$ ), the more consistently Pd leaches, and therefore, a higher reaction rate is observed. In addition, a much slower reaction is observed when $\mathrm{Pd} / \mathrm{CeO}_{2}$ is used as the catalyst, which shows the lowest $\mathrm{PZC}$ value within the series of $\mathrm{Pd} / \mathrm{M}_{\mathrm{x}} \mathrm{O}_{\mathrm{y}}$. Consequently, prolonged recycling is possible in the case of $\mathrm{Pd} / \mathrm{CeO}_{2}$ due to minimal palladium leaching. Thus, from the studied series of $\mathrm{Pd} / \mathrm{M}_{\mathrm{x}} \mathrm{O}_{\mathrm{y}}$ type catalysts, $\mathrm{Pd} / \mathrm{CeO}_{2}$ was chosen as superior precatalyst based on the following considerations: (i) it can be recycled several times without a significant decrease of activity (prolonged recyclability) and (ii) the organic product is sparsely contaminated since there is minimal leaching of palladium into the solution. 


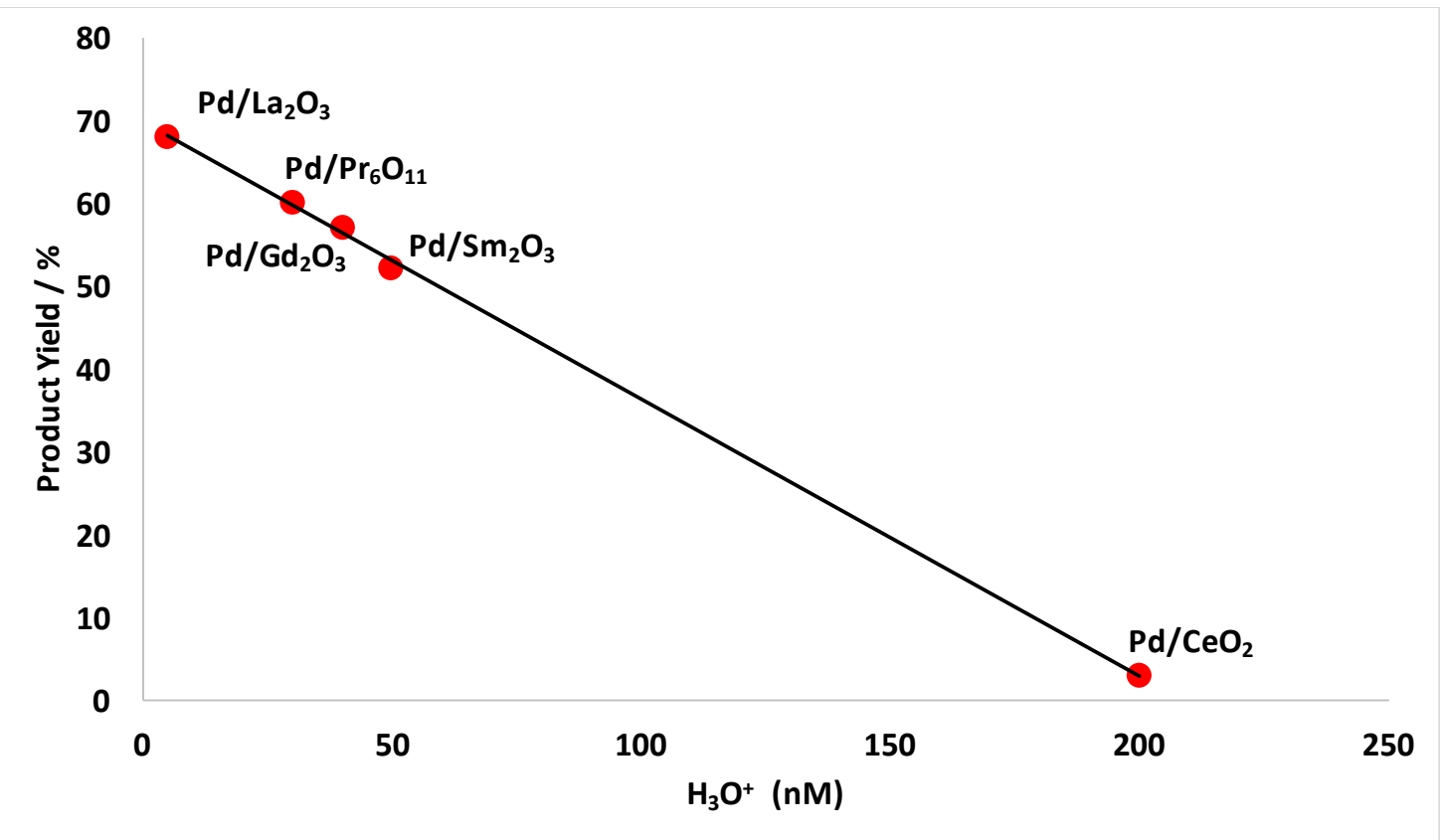

Figure 4. Cross-coupling reaction yield (after $2 \mathrm{~min}$ of reaction) vs. proton molar concentration $\left(10^{-\mathrm{PZC}}\right)$ for $\mathrm{Pd} / \mathrm{M}_{\mathrm{x}} \mathrm{O}_{\mathrm{y}}[10]$ (Adapted with permission from Springer Nature).

Alternatively, the physicochemical properties of the support can be enhanced through substitution of a foreign metal ion in its lattice structure [43]. The substitution of foreign metal ions into the lattice of reducible oxides such as $\mathrm{CeO}_{2}$ and $\mathrm{TiO}_{2}$ to form ionic solid-solution oxides $\left(\mathrm{Ce}_{1-\mathrm{x}} \mathrm{M}_{\mathrm{x}} \mathrm{O}_{2-\delta}\right.$ or $\mathrm{Ti}_{1-\mathrm{x}} \mathrm{M}_{\mathrm{x}} \mathrm{O}_{2-\delta}$ ) has given materials which show high activity for a variety of catalytic reactions, especially in gas-phase oxidation reactions [11,43-48]. However, such catalysts have rarely been applied to C-C cross-coupling reactions [49-51]. Recently, Burange and co-workers [44] reported that the ionic ceria-zirconia $\left(\mathrm{CeZrO}_{4-\delta}\right)$ solid-solution oxides exhibit high redox properties and thermal stability that make them better catalyst supports than the pure metal oxide counterparts [52]. Hence, $\mathrm{CeZrO}_{4-\delta}$ solid-solution oxide was used to immobilise palladium nanoparticles and the resultant catalyst $\left(\mathrm{Pd} / \mathrm{CeZrO}_{4-\delta}\right)$ was explored in Suzuki cross-coupling reactions (Figure 5). The mechanistic investigation proved that the redox couple $\left(\mathrm{Ce}^{4+} / \mathrm{Ce}^{3+}\right)$ in the $\mathrm{CeZrO}_{4-\delta}$ support enhances the catalytic activity through creation of oxygen vacancies. Furthermore, the support displayed strong metal-support ( $\left.\mathrm{Pd}-\mathrm{CeZrO} \mathrm{Zr}_{4-\delta}\right)$ interactions and hence, "no leaching" was observed. Thus, it was concluded that the reactions were "truly" heterogeneous [52].

Lichtenegger and co-workers [53] extended the Burange et al. [52] study by directly incorporating palladium ions into the lattice of the support (ceria), instead of modifying the properties of the support with a foreign metal. In their study, they used $\mathrm{CeO}_{2}$ and $\mathrm{SnO}_{2}$ as supports and prepared a series of corresponding ionic solid-solution oxides: $\mathrm{Ce}_{0.99} \mathrm{Pd}_{0.01} \mathrm{O}_{2-\delta}, \mathrm{Ce}_{0.79} \mathrm{Sn}_{0.2} \mathrm{Pd}_{0.01} \mathrm{O}_{2-\delta}$, $\mathrm{Ce}_{0.495} \mathrm{Sn}_{0.495} \mathrm{Pd}_{0.01} \mathrm{O}_{2-\delta}, \mathrm{Ce}_{0.20} \mathrm{Sn}_{0.79} \mathrm{Pd}_{0.01} \mathrm{O}_{2-\delta}$, and $\mathrm{Sn}_{0.99} \mathrm{Pd}_{0.01} \mathrm{O}_{2-\delta}$. These catalysts were thoroughly explored in Suzuki coupling reactions of phenylboric acid with various bromoarenes (Figure 6). The $\mathrm{Ce}_{0.79} \mathrm{Sn}_{0.2} \mathrm{Pd}_{0.01} \mathrm{O}_{2-\delta}, \mathrm{Ce}_{0.20} \mathrm{Sn}_{0.79} \mathrm{Pd}_{0.01} \mathrm{O}_{2-\delta}$, and $\mathrm{Sn}_{0.99} \mathrm{Pd}_{0.01} \mathrm{O}_{2-\delta}$ catalysts showed extraordinarily high activities in Suzuki cross-coupling reactions, while the binary solid-solution oxide $\mathrm{Ce}_{0.99} \mathrm{Pd}_{0.01} \mathrm{O}_{2-\delta}$ proved to be the least active catalyst. Thus, the Sn containing catalysts were shown to be more active; however, the results do not show a clear correlation between Sn loadings and the catalytic activity. Furthermore, complete conversion was achieved in five subsequent reactions for all catalysts, except when $\mathrm{Ce}_{0.99} \mathrm{Pd}_{0.01} \mathrm{O}_{2-\delta}$ and $\mathrm{Ce}_{0.495} \mathrm{Sn}_{0.495} \mathrm{Pd}_{0.01} \mathrm{O}_{2-\delta}$ were used. 

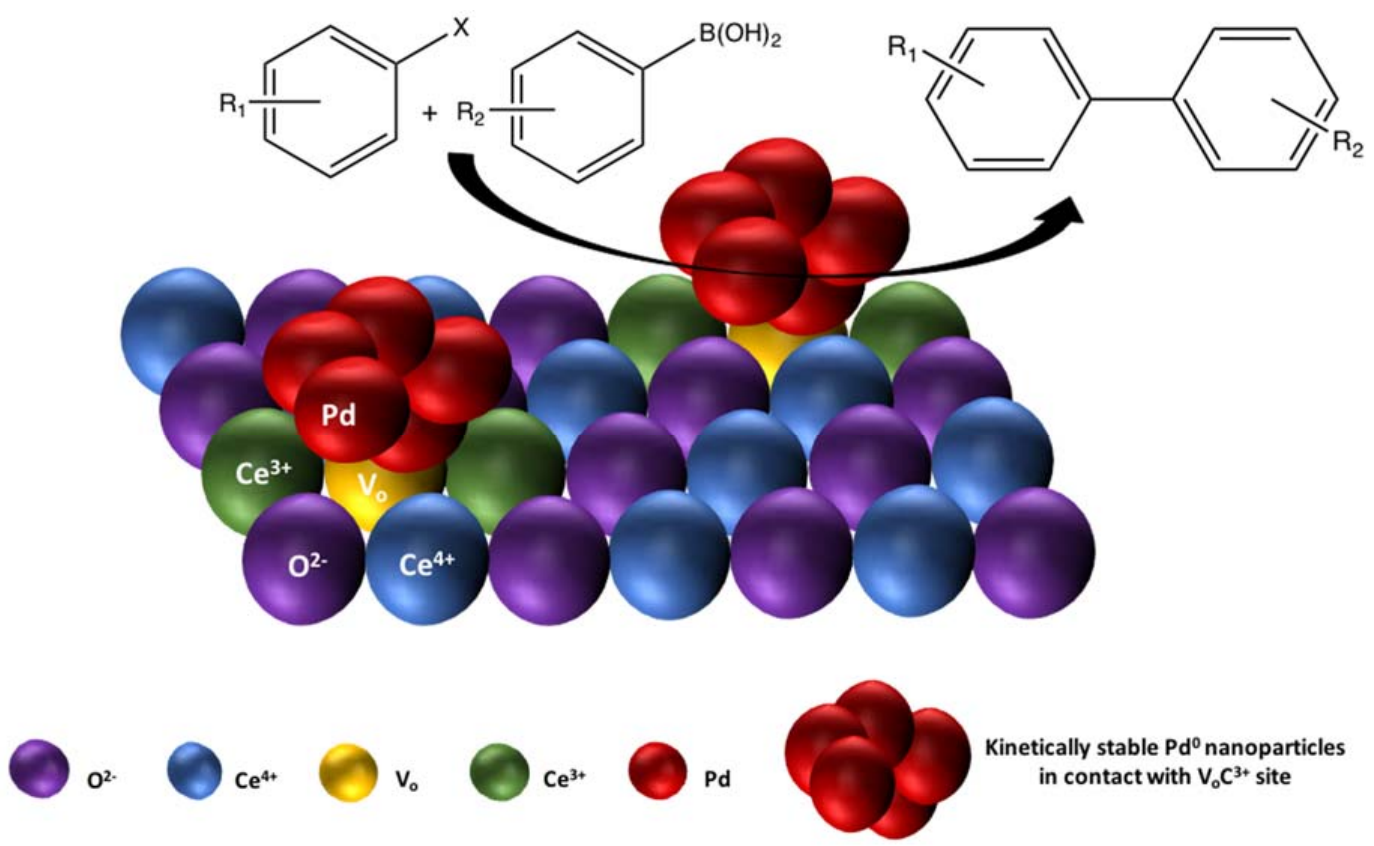

Figure 5. Plausible heterogeneous catalytic reaction mechanism suggested for Suzuki cross-coupling over the $\mathrm{Pd} / \mathrm{CeZrO}_{4-\delta}$ redox catalyst [52] (Adapted with permission from John Wiley and Sons).

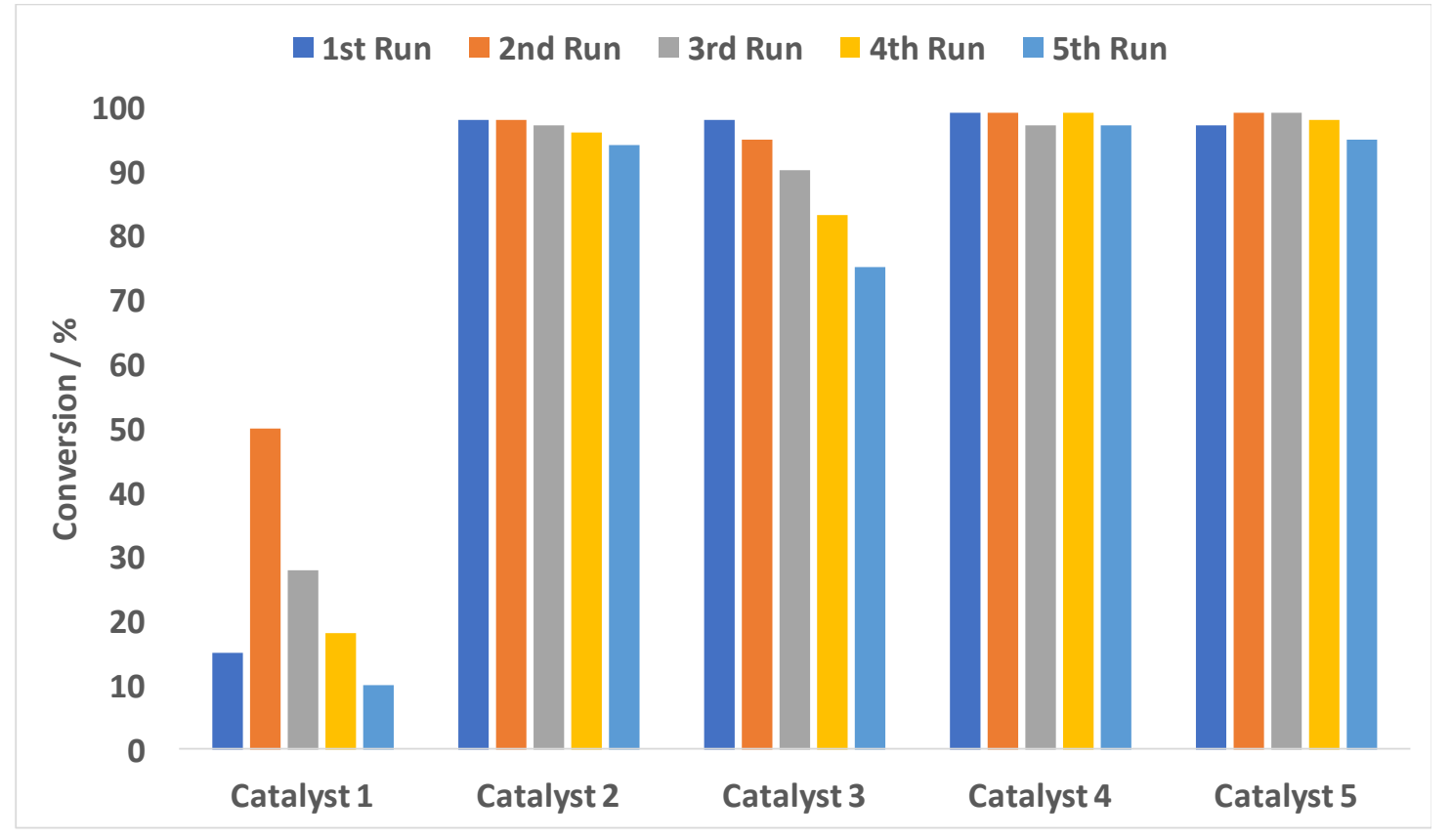

Figure 6. The Suzuki coupling of 4-bromotoluene with phenylboronic acid (after $30 \mathrm{~min}$ ) using $0.5 \mathrm{~mol} \%$ Pd. Catalyst 1: $\mathrm{Ce}_{0.99} \mathrm{Pd}_{0.01} \mathrm{O}_{2-\delta}$, Catalyst 2: $\mathrm{Ce}_{0.79} \mathrm{Sn}_{0.2} \mathrm{Pd}_{0.01} \mathrm{O}_{2-\delta}$, Catalyst 3: $\mathrm{Ce}_{0.495} \mathrm{Sn}_{0.495} \mathrm{Pd}_{0.01} \mathrm{O}_{2-\delta}$, Catalyst 4: $\mathrm{Ce}_{0.20} \mathrm{Sn}_{0.79} \mathrm{Pd}_{0.01} \mathrm{O}_{2-\delta}$, and Catalyst 5: $\mathrm{Sn}_{0.99} \mathrm{Pd}_{0.01} \mathrm{O}_{2-\delta}$ [53] (Adapted with permission from Elsevier).

Thorough catalyst leaching, recovery and recyclability studies were conducted and the results demonstrate a clear correlation between reactivity and amount of leached palladium (Figure 7). Hence, these findings also support the hypothesis that the coupling reaction is catalyzed by small amounts of leached palladium via a homogeneous reaction mechanism. 


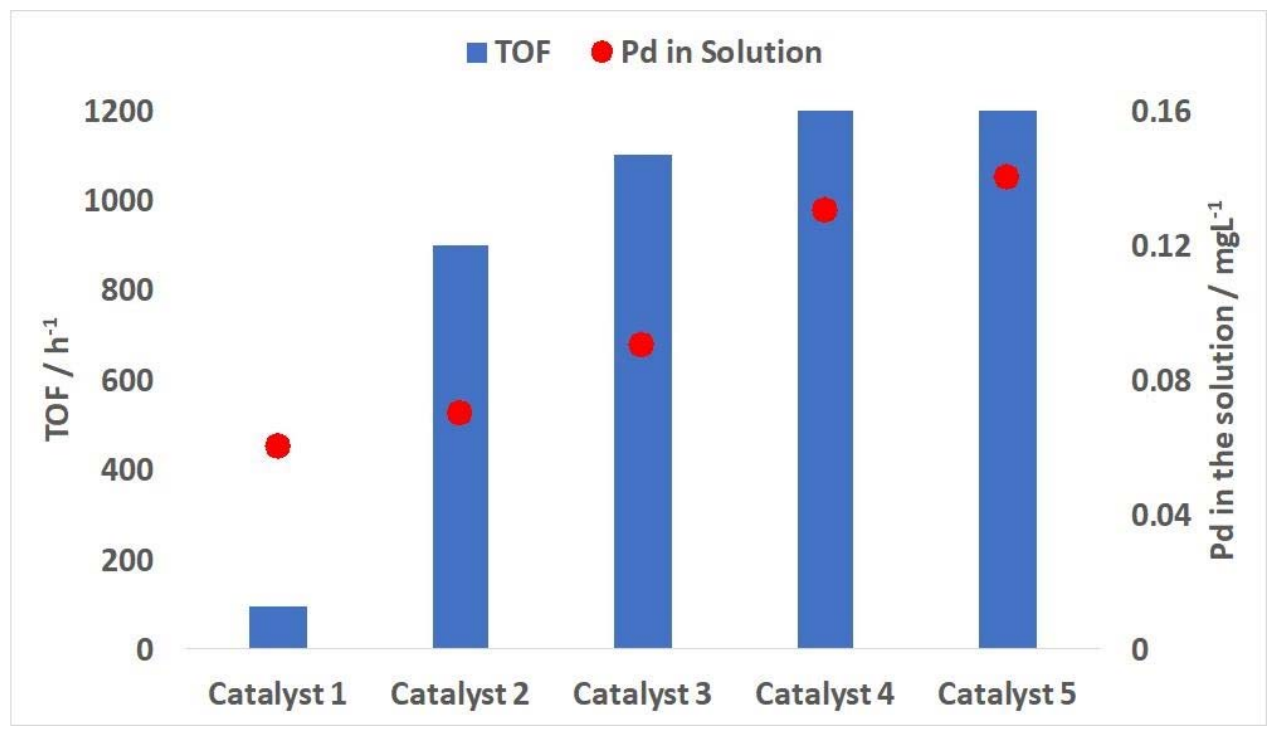

Figure 7. Turnover frequency (TOF) vs. Pd-concentration in the solution (Pd leached). Catalyst 1: $\mathrm{Ce}_{0.99} \mathrm{Pd}_{0.01} \mathrm{O}_{2-\delta}$, Catalyst 2: $\mathrm{Ce}_{0.79} \mathrm{Sn}_{0.2} \mathrm{Pd}_{0.01} \mathrm{O}_{2-\delta}$, Catalyst 3: $\mathrm{Ce}_{0.495} \mathrm{Sn}_{0.495} \mathrm{Pd}_{0.01} \mathrm{O}_{2-\delta}$, Catalyst 4: $\mathrm{Ce}_{0.20} \mathrm{Sn}_{0.79} \mathrm{Pd}_{0.01} \mathrm{O}_{2-\delta}$, and Catalyst 5: $\mathrm{Sn}_{0.99} \mathrm{Pd}_{0.01} \mathrm{O}_{2-\delta}$ [53] (Adapted with permission from Elsevier).

To further explore this concept of "release-capture mechanism" by ionic solid-solution oxides catalysts, we have reported on the application of a highly $\mathrm{Pd}$ substituted ceria catalyst $\left(\mathrm{Pd}_{0.09} \mathrm{Ce}_{0.91} \mathrm{O}_{2-\delta}\right)$ in the Heck cross-coupling reaction [49]. Good to excellent yields of substituted olefins were obtained with this $\mathrm{Pd}_{0.09} \mathrm{Ce}_{0.91} \mathrm{O}_{2-\delta}$ solid-solution catalyst. However, our findings also revealed that the catalysis occurs over the reduced two phase $\mathrm{Pd}^{0} / \mathrm{CeO}_{2}$ and not on the as prepared monophasic $\mathrm{Pd}_{0.09} \mathrm{Ce}_{0.91} \mathrm{O}_{2-\delta}$ (Scheme 4). In addition, it was observed that the $\mathrm{Pd}^{0} / \mathrm{CeO}_{2}$ formed in situ can be easily recovered and reused for several times without any significant loss in efficiency and only a negligible amount of palladium was detected in the product solution $(0.35 \mathrm{ppm})$. The low level of palladium concentration in the product solution further highlights the excellent ability of ceria to re-adsorb leached palladium species, as discussed earlier.

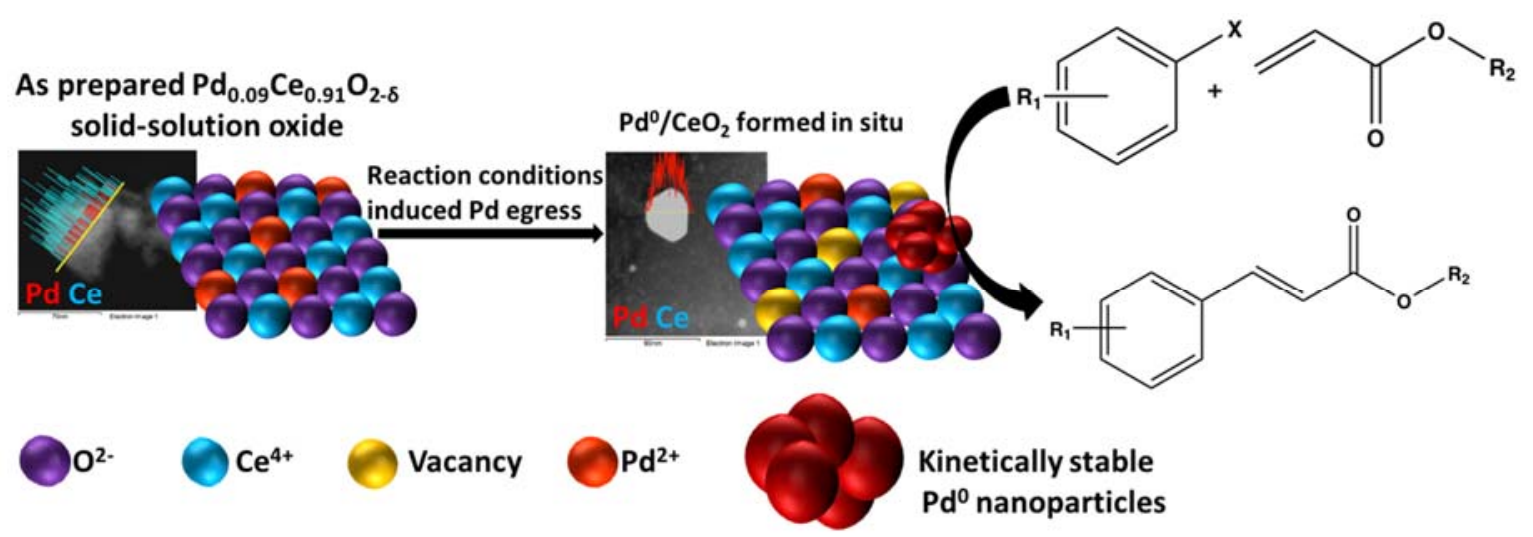

Scheme 4. Proposed Heck coupling reaction mechanism catalysed by the $\mathrm{Pd}_{0.09} \mathrm{Ce}_{0.91} \mathrm{O}_{2-\delta}$ precatalyst [49] (Adapted with permission from Elsevier).

We were also able to show that the reaction conditions greatly affect the catalysis. In this regard, we investigated the application of a $\mathrm{Pd}_{0.04} \mathrm{Cu}_{0.04} \mathrm{Ce}_{0.92} \mathrm{O}_{2-\delta}(\mathrm{PdCuCeO})$ solid-solution oxide on Suzuki cross-coupling reactions (Scheme 5) [50]. The reactions were carried-out under milder and more environmentally friendly reaction conditions, using water as sole solvent and tetrapropylammonium 
bromide (TPAB) as a phase transfer catalyst. The catalytic results displayed good functional group tolerance and good to excellent yields of substituted biphenyls were obtained. However, catalyst leaching and recyclability studies revealed that $\mathrm{PdCuCeO}$ acts as a $\mathrm{Pd}$ reservoir and that the reactions were essentially quasi-heterogeneous, occurring over recoverable Pd/TPAB aggregates (generated in situ). The PdCuCeO solid-solution catalyst was recovered and recycled three times; however, its catalytic activity declined with each subsequent recycle.

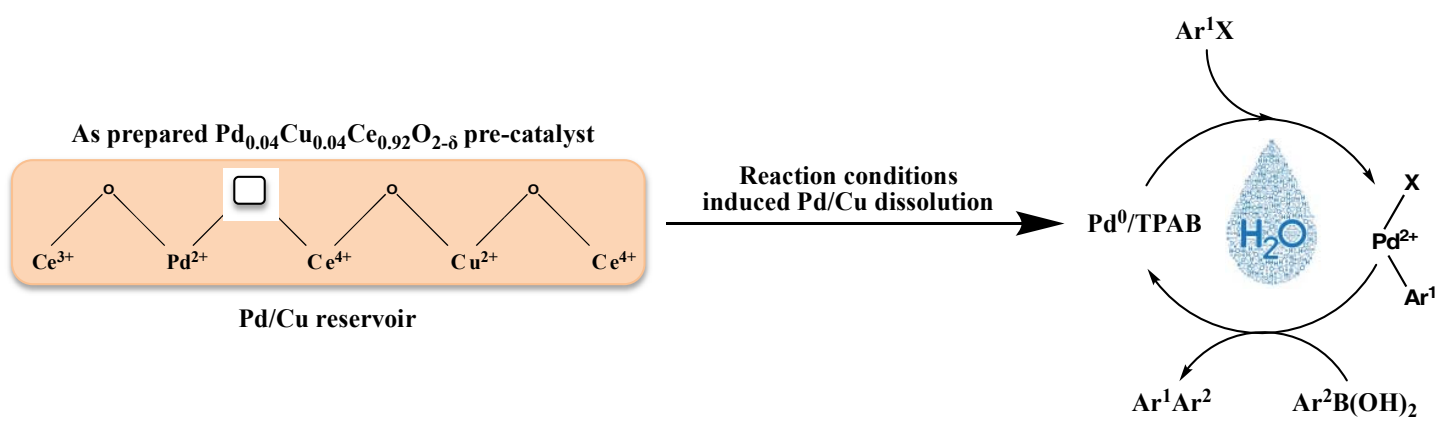

Scheme 5. A proposed reaction mechanism for the $\mathrm{Pd}_{0.04} \mathrm{Cu}_{0.04} \mathrm{Ce}_{0.92} \mathrm{O}_{2-\delta}$ ( $\mathrm{PdCuCeO}$ )tetrapropylammonium bromide (TPAB) catalysed quasi-heterogeneous SM (Suzuki-Miyaura) cross-coupling reactions [50].

Hence, it can be concluded that most of the reported ionic solid-solution oxides catalysts are simply precatalysts that act as a palladium reservoir for the active palladium species. Therefore, the observed high activity and recyclability of the catalysts could be attributed to a Pd release-capture mechanism, as discussed earlier.

\section{Palladium Nanoparticle Immobilised on Magnetic Supports}

Recent studies show that magnetic nanoparticles are excellent supports for various catalysts [54-61]. Additionally, the magnetic properties can be exploited to improve catalyst separation from previous filtration and centrifugation methods. Supported palladium magnetic catalysts have the benefits of easy recovery from the reaction media by the application of an external magnetic field (Figure 8) [57]. Magnetic nanoparticles can be categorized into four main groups, namely; metals $(\mathrm{Fe}, \mathrm{Co}, \mathrm{Ni})$, alloys (FePt, FePd), ferrites $\left(\mathrm{CoFe}_{2} \mathrm{O}_{4}, \mathrm{CuFe}_{2} \mathrm{O}_{4}\right)$, and most notably metal oxides (FeO, $\mathrm{Fe}_{2} \mathrm{O}_{3}, \mathrm{Fe}_{3} \mathrm{O}_{4}$ ). Iron oxides are the most widely employed in literature because they have stronger magnetic properties and can be synthesized easily by co-precipitation methods [62].

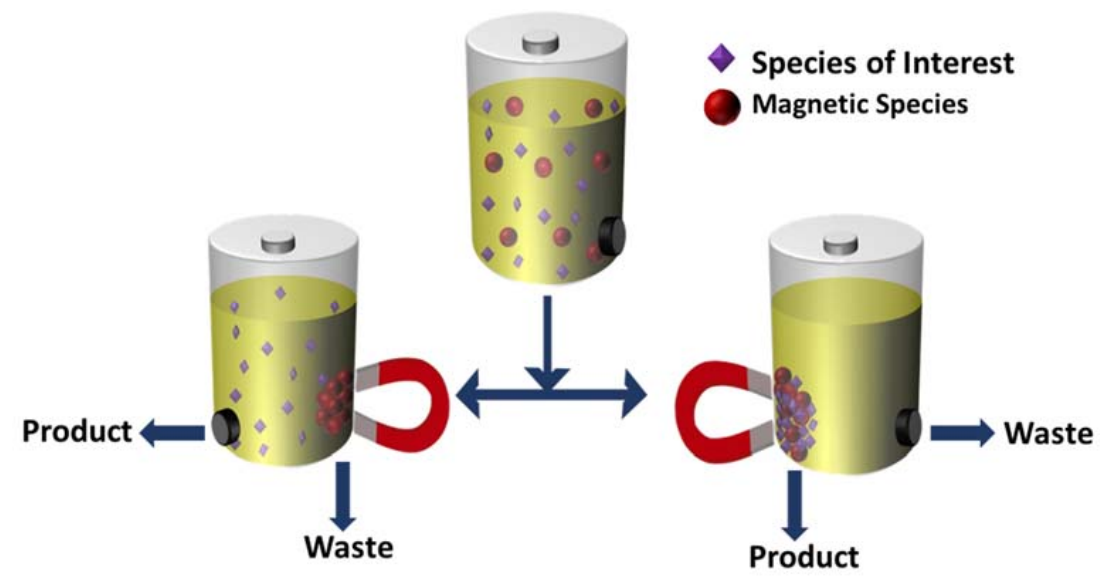

Figure 8. Examples of the use of magnetic separation through the application of an external magnetic field [63] (Adapted with permission from The Royal Society of Chemistry). 
A growing number of these magnetic supports have been applied in the development of magnetically recoverable palladium based heterogeneous catalysts for $\mathrm{C}-\mathrm{C}$ cross-coupling reactions. Nasrollahzadeh and co-workers have explored the application of $\mathrm{Pd} / \mathrm{Fe}_{3} \mathrm{O}_{4}$ magnetic nanoparticles as an efficient catalyst for $\mathrm{C}-\mathrm{C}$ cross-coupling reactions [64]. The $\mathrm{Pd} / \mathrm{Fe}_{3} \mathrm{O}_{4}$ magnetic catalyst was found to be stable during the Suzuki coupling reaction and good yields (83-95\%) were obtained over a wide range of substrates. At the end of the Suzuki reaction the catalyst was recovered by the application of an external magnet, and successively reused five times without significant loss of activity.

Although bare or "naked" iron oxide nanoparticles have been shown to be efficient supports for cross-coupling reactions, the immobilization of palladium directly on the iron oxide occasionally suffers from aggregation or surface oxidation. The oxidation and agglomeration of magnetic nanoparticles results in the loss of their magnetism; thus, it is crucial to develop efficient strategies to strengthen their chemical stability [60]. In this regard, a wide range of stabilizing or coating materials, including organic stabilizers (polymers and surfactants) and inorganic stabilizers (silica and carbon materials), have been used to protect magnetic nanoparticles [60,65]. In this direction, Kumar et al. [66] developed efficient $\mathrm{C} @ \mathrm{Fe}_{3} \mathrm{O}_{4}$ magnetic core-shell nano-spheres by coating the $\mathrm{Fe}_{3} \mathrm{O}_{4}$ nanoparticle with a carbon shell to protect them from being corrupted or oxidized under cross-coupling reaction conditions. Palladium was then immobilised on the synthesized $\mathrm{C}_{0} \mathrm{Fe}_{3} \mathrm{O}_{4}$ magnetic core-shell to form a structurally stable $\mathrm{Pd} / \mathrm{C} \mathrm{Fe}_{3} \mathrm{O}_{4}$ catalyst (Figures 9 and 10). This catalyst was efficiently used as a heterogeneous catalyst for Heck cross-coupling reactions and good to excellent yields were obtained. The catalyst was easily separated from the reaction mixture through application of an external magnet and the catalyst was reused five times without any significant drop in activity. The authors claim that this catalytic system is "truly heterogeneous" even though some leaching was observed. They concluded that their catalytic system is advantageous because of its heterogeneity, high stability, gram scale applicability, magnetic separability, and consequent reusability [66].

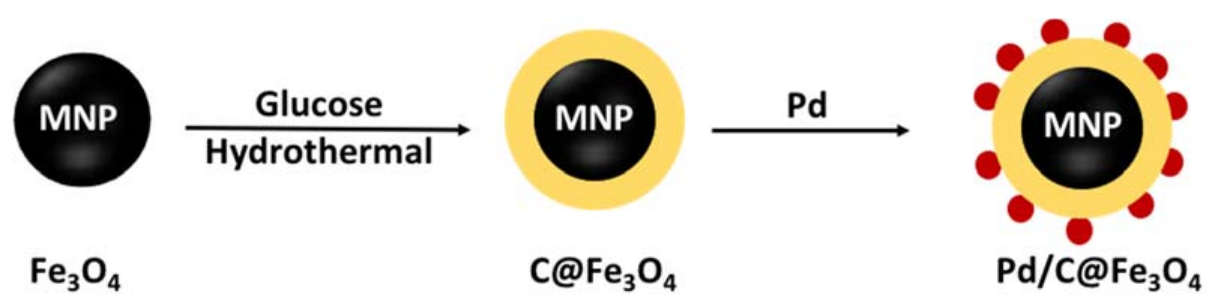

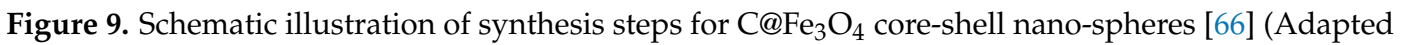
with permission from Elsevier).

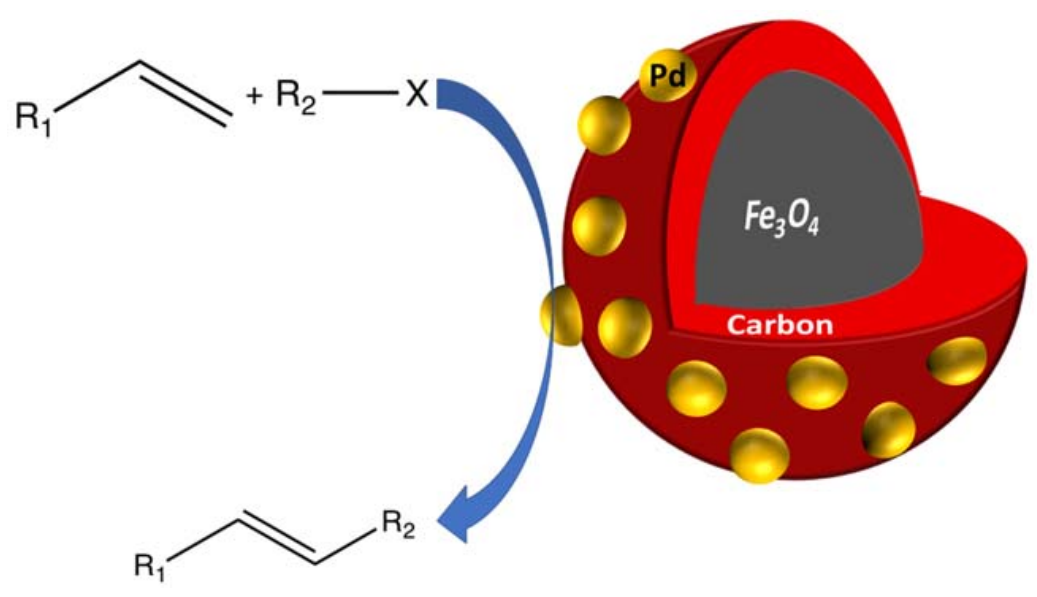

Figure 10. Graphical illustration of Pd/C@ $\mathrm{Fe}_{3} \mathrm{O}_{4}$ catalysed cross-coupling reactions [66] (Adapted with permission from Elsevier). 
The coated magnetic nanoparticles can be further modified by functionalising their surface with various functional groups (Figure 11). The functionalization of the surface of magnetic nanomaterials is an important step in the design of supported catalysts, because it significantly improves the physical and chemical properties of the magnetic supports [63].

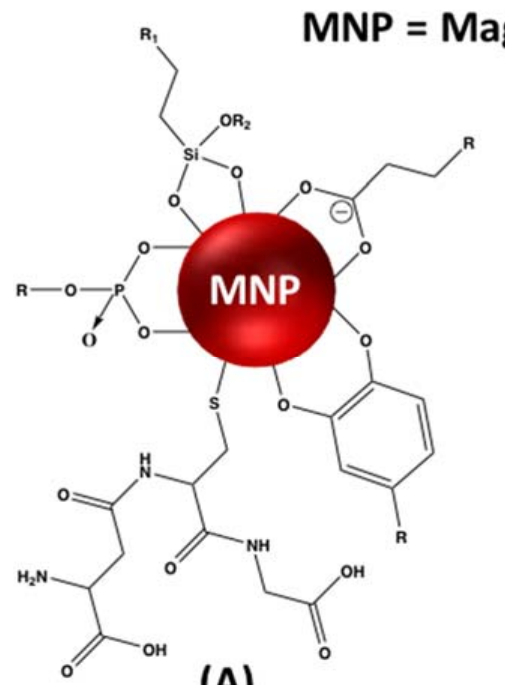

(A)

(C)

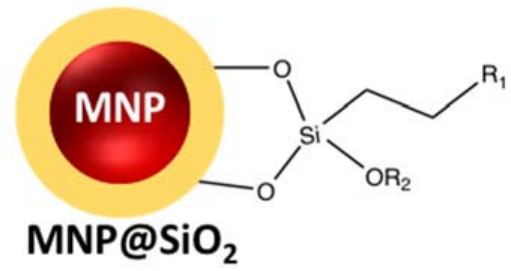

(B)

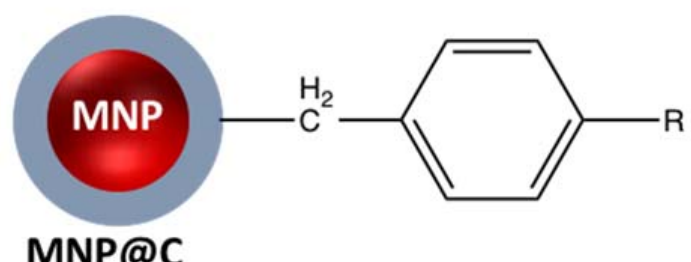

MNP@C

Figure 11. Different approaches to functionalize magnetic nanoparticles (MNPs): (A) iron oxide MNPs; (B) silica-coated MNPs; and (C) carbon-coated MNPs [63] (Adapted with permission from The Royal Society of Chemistry).

Heidari and co-worker [67] used isoniazide to functionalize the surface of the $\mathrm{Fe}_{3} \mathrm{O}_{4} @ \mathrm{SiO}_{2}$ magnetic nano-support (Figure 12). The isoniazide groups were used as linkers to immobilize palladium nanoparticles and prevent agglomeration on the surface of the $\mathrm{Fe}_{3} \mathrm{O}_{4} @ \mathrm{SiO}_{2}$ magnetic nano-support [67]. The resulting material, $\mathrm{Fe}_{3} \mathrm{O}_{4} @ \mathrm{SiO}_{2} /$ isoniazide/Pd catalyst, was explored as a heterogeneous catalyst in Suzuki coupling reactions and good to excellent yields were obtained. The authors reported that the benefits of their heterogeneous catalyst system were its high efficiency and reuse was easily achieved through the use of a magnet. They were able to recover and recycle their catalyst six times without any noticeable loss in activity.

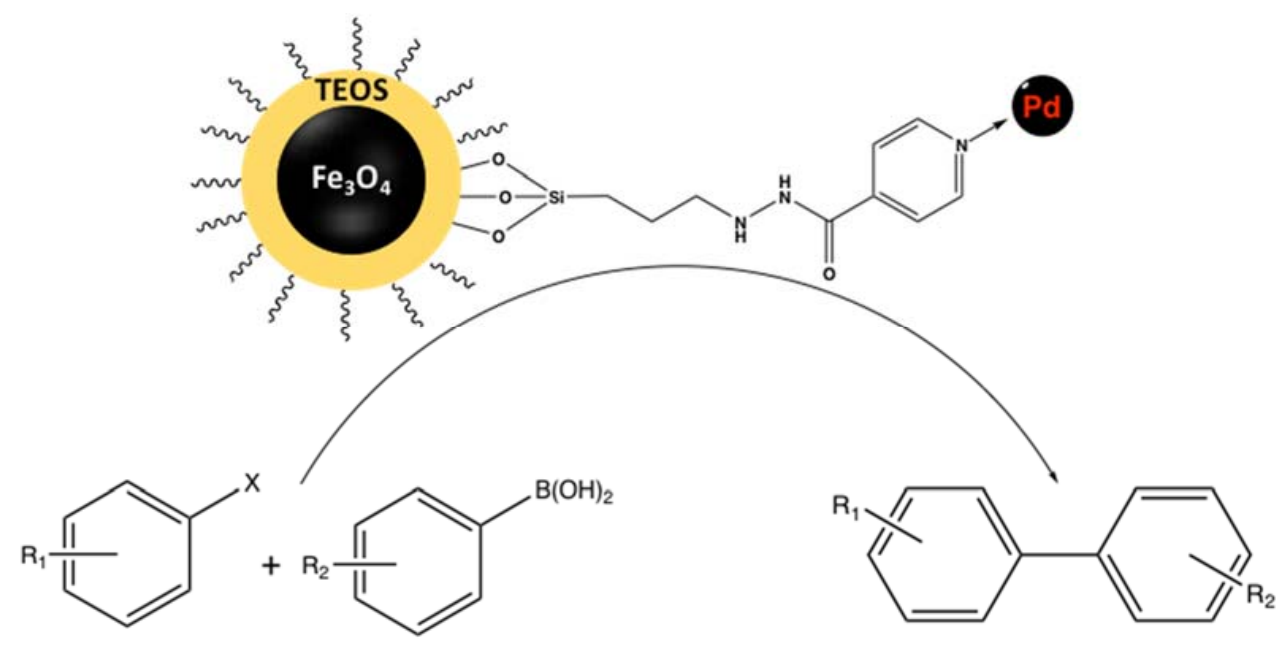

Figure 12. $\mathrm{Fe}_{3} \mathrm{O}_{4} @ \mathrm{SiO}_{2}$ /isoniazide/Pd mediated Suzuki cross-coupling reaction [67] (Adapted with permission from Elsevier). 
An interesting but slightly different approach was reported by Khalili and co-workers [12], who supported palladium nanoparticles on an amino-vinyl silica functionalized magnetic carbon nanotube (CNT). Their core-shell contains $\mathrm{CNT} @ \mathrm{Fe}_{3} \mathrm{O}_{4} @ \mathrm{SiO}_{2}-\mathrm{Pd}$ in which the functionalized $\mathrm{SiO}_{2}$ helps with the stability of the Pd nanoparticles and is also responsible for the reduction of $\mathrm{Pd}$ (II) to $\operatorname{Pd}(0)$ without the need for adding external reducing agents (Figure 13). This catalyst was successfully applied to Heck and Suzuki cross-coupling reactions and high yields were obtained. In addition, the catalyst exhibited good recyclability, and was used for six consecutive recycles without a significant loss in catalytic activity.

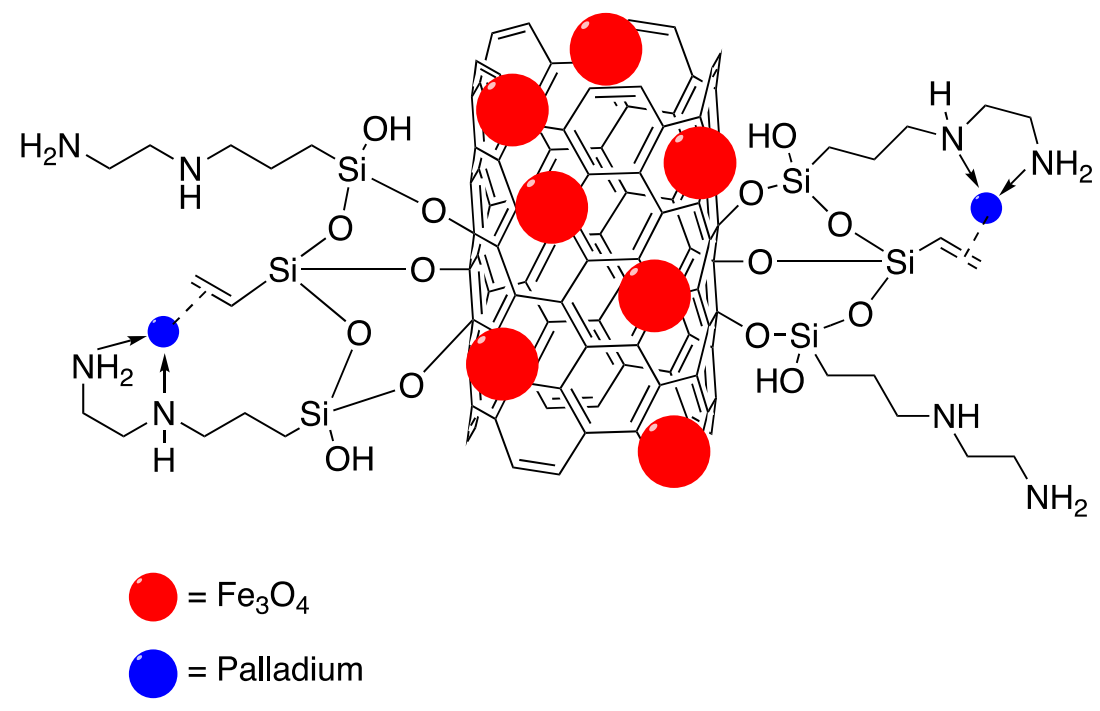

Figure 13. A graphical illustration of the $\mathrm{CNT} @ \mathrm{Fe}_{3} \mathrm{O}_{4} @ \mathrm{SiO}_{2}-\mathrm{Pd}$ catalyst [12] (Adapted with permission from Springer Nature).

There are also numerous examples where organopalladium complexes, instead of palladium nanoparticles, have been immobilised on magnetic supports [68,69]. Recently, Collinson and co-workers [68] prepared a [(NHC)Pd(allyl)Cl] complex, bearing an $N$-heterocyclic carbene (NHC) and immobilised it on silica-coated magnetic nanoparticles (Scheme 6). Their strategy tries to combine the high activity of palladium-NHC catalysts with the facile separation and recyclability of a heterogeneous catalyst. The catalyst was then explored on Suzuki coupling reactions and good to excellent yields were obtained with a variety of substrates. However, the immobilised palladium complex could not be reused because the catalyst disassembled or decomposed under Suzuki coupling reaction conditions. The recycled catalyst only achieved $20 \%$ yield compared to the $90 \%$ yield that was obtained in its first use. The authors suspected that the base was responsible for the detachment of the magnetic silica linker.

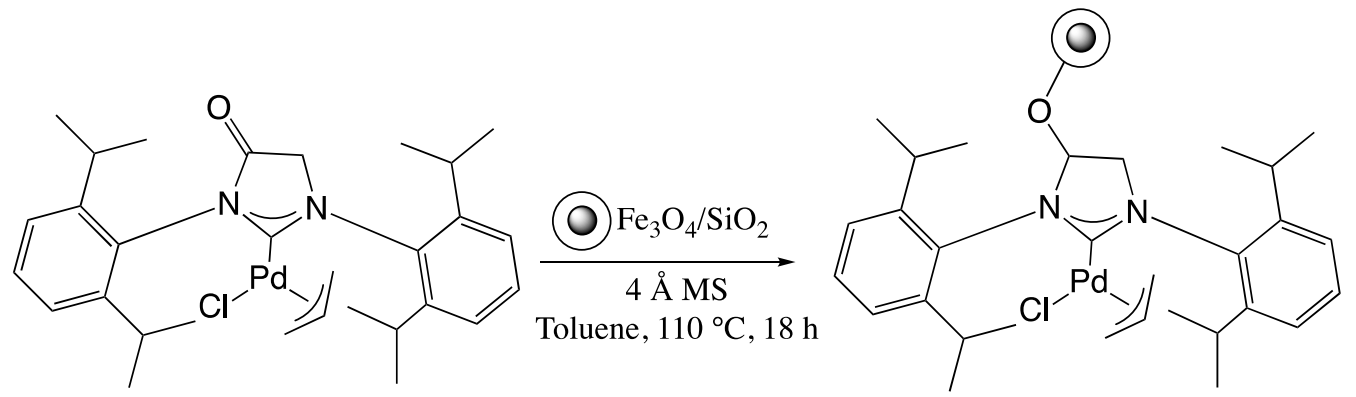

Scheme 6. Immobilisation of the [N-heterocyclic carbene (NHC)Pd(allyl)Cl] complex on silica-coated magnetic nanoparticles [68] (Adapted with permission from Elsevier). 
Better results were obtained by Fareghi-Alamdari et al. [69] who supported bis( $N$-heterocyclic carbene) palladium complex on silica coated magnetic nanoparticles (Figure 14).

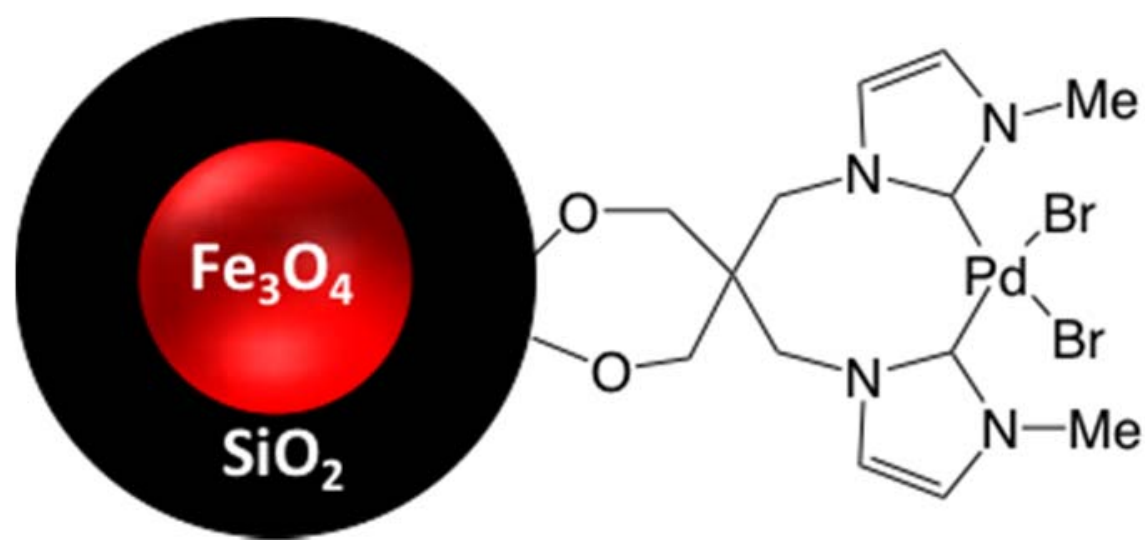

Figure 14. Bis( $N$-heterocyclic carbene) palladium complex supported on silica coated magnetic nanoparticles [69] (Adapted with permission from John Wiley and Sons).

Their catalyst was efficiently used for Suzuki coupling reactions and at the end of the reaction, it was separated though application of an external magnet and recycled for six consecutive reactions. Hence, it not easy to identify the reaction parameters that caused the Collinson and co-workers [68] catalytic system to be unrecyclable because the reaction conditions are different (Table 4). However, the most obvious difference is the choice of the base; Collinson and co-workers used $\mathrm{NaOH}$, which is very harsh, while Fareghi-Alamdari et al. used $\mathrm{K}_{2} \mathrm{CO}_{3}$. Hence, optimisation of reaction conditions is crucial in developing efficient and more robust catalytic systems.

Table 4. The reaction conditions for Suzuki cross-coupling reactions catalysed by supported palladium complexes in references $[68,69]$.

\begin{tabular}{cccc}
\hline & \multicolumn{3}{c}{ Reaction Conditions } \\
\cline { 2 - 4 } & Solvent & Base & Temperature $\left({ }^{\circ} \mathrm{C}\right)$ \\
\hline${\text { Collinson et al. [68] }{ }^{\mathrm{a}}}$ & Isopropanol & $\mathrm{NaOH}$ & 60 \\
Fareghi-Alamdari et al. [69] $^{\mathrm{b}}$ & $\mathrm{DMF} / \mathrm{H}_{2} \mathrm{O}$ & $\mathrm{K}_{2} \mathrm{CO}_{3}$ & 80 \\
\hline
\end{tabular}

${ }^{a}$ Reaction conditions: Bromotoluene $(1.0 \mathrm{mmol})$, phenylboronic acid $(1.05 \mathrm{mmol}), \mathrm{NaOH}(1.1 \mathrm{mmol})$, catalyst $(1 \mathrm{~mol} \% \mathrm{Pd})$, isopropanol $(1 \mathrm{~mL}) .{ }^{\mathrm{b}}$ Reaction conditions: Bromotoluene $(1.0 \mathrm{mmol})$, phenylboronic acid $(1.2 \mathrm{mmol})$, $\mathrm{K}_{2} \mathrm{CO}_{3}(1.5 \mathrm{mmol})$, catalyst $(0.12 \mathrm{~mol} \% \mathrm{Pd}), \mathrm{DMF} / \mathrm{H}_{2} \mathrm{O}(2: 1,3 \mathrm{~mL})$.

In summary, the literature shows that magnetic nanoparticle-based catalytic systems have a huge potential in solving the recoverability and recyclability challenges [57].

\section{Polymer Supported Palladium Nanoparticles}

Literature reports have repeatedly shown that palladium nanoparticles can be efficiently supported on polymer frameworks [70-77]. Recently, Nemygina and co-workers immobilised various palladium precursors $\left(\mathrm{PdCl}_{2}, \mathrm{PdCl}_{2}\left(\mathrm{CH}_{3} \mathrm{CN}\right)_{2}\right.$, and $\left.\mathrm{PdCl}_{2}(\mathrm{PhCN})_{2}\right)$ on amino-functionalized hyper-crosslinked polystyrene [78]. They then evaluated the influence of palladium oxidation state $(\mathrm{Pd}(\mathrm{II})$ or $\mathrm{Pd}(0))$ on the rate of Suzuki cross-coupling of 4-bromoanisole and phenylboronic acid. Their results revealed that the catalyst impregnated with a $\mathrm{PdCl}_{2}\left(\mathrm{CH}_{3} \mathrm{CN}\right)_{2}$ precursor resulted in better catalytic activity (Scheme 7). The $\mathrm{PdCl}_{2}\left(\mathrm{CH}_{3} \mathrm{CN}\right)_{2}$ precursor was believed to be more active because it experienced less hydrolysis and precipitation in comparison with $\mathrm{PdCl}_{2}$ and $\mathrm{PdCl}_{2}\left(\mathrm{PhCN}_{2}\right.$ under Suzuki coupling reaction conditions. Lastly, they observed that unreduced, $\operatorname{Pd}(\mathrm{II})$ containing pre-catalyst were more active [78]. 


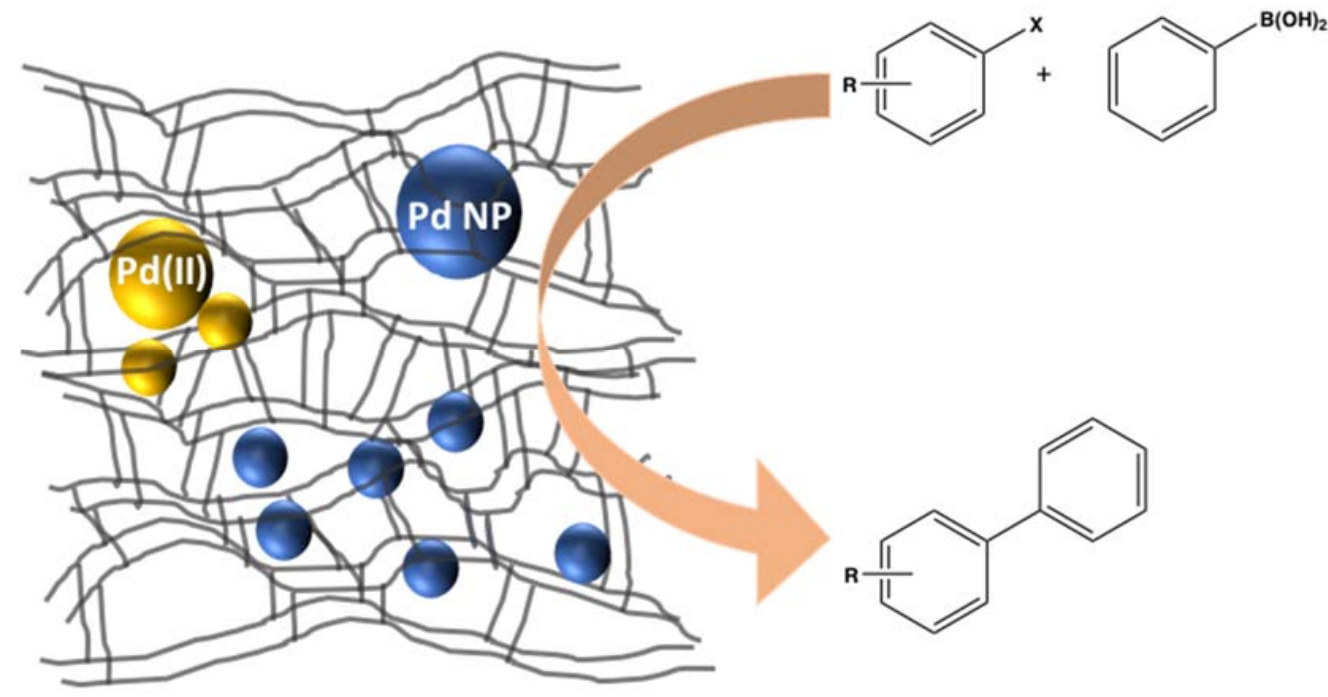

Scheme 7. Catalysts for Suzuki cross-coupling based on functionalized hyper-crosslinked polystyrene [78] (Adapted with permission from American Chemical Society).

Another interesting strategy for immobilising palladium on a polymer was reported by Li and co-workers [79], who synthesised a robust and flexible cellulose sponge using a dual-cross-linking cellulose nanofiber (CNF) with $\gamma$-glycidoxypropyltrimethoxysilane (GPTMS) and polydopamine (PDA) (Scheme 8). The characterisation results revealed that the palladium nanoparticles were homogeneously dispersed on the surface of the cellulose nanofiber with a narrow size distribution. The catalyst was successfully applied to heterogeneous Suzuki and Heck cross-coupling reactions. Leaching of palladium was negligible and the catalysts could be conveniently separated from the products and reused for six times without loss of activity [79].

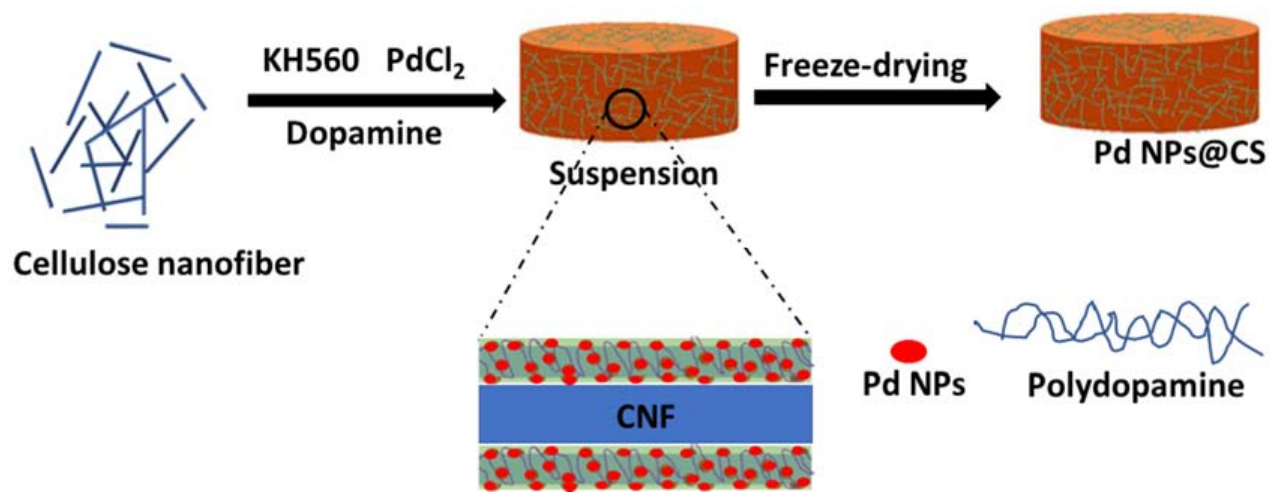

Scheme 8. Schematic of the stepwise formation of cellulose sponge supported palladium nanoparticles [79] (Adapted with permission from American Chemical Society).

\section{Palladium Nanoparticles Immobilized on Hybrid Inorganic-Organic Material}

The hybrid inorganic-organic materials are crystalline systems in which both inorganic and organic structural elements co-exist within a single phase [80]. These hybrid inorganic-organic materials are gaining popularity in cross-coupling reactions due to their tunable pore size, high surface areas, high crystallinity, and structural diversity [81-87]. Most hybrid inorganic-organic materials are synthesised through functionalization of the support surface with appropriate functional groups. This allows for a better control of the dimensions, dispersion and stability of the palladium nanoparticles. Metal-organic frameworks (MOFs) are one of the most popular classes of hybrid inorganic-organic 
materials and they are frequently explored as suitable palladium supports in heterogeneous cross-coupling reactions. For example, Shaikh and co-workers [88] used a zeolitic imidazolate framework (ZIF) to develop robust ZIF-supported palladium nanoparticles as a heterogeneous catalyst for Heck cross-coupling reactions (Figure 15). The Pd/ZIF catalyst was found to be highly efficient and could be re-used up to four times without any loss in catalytic efficiency [88].

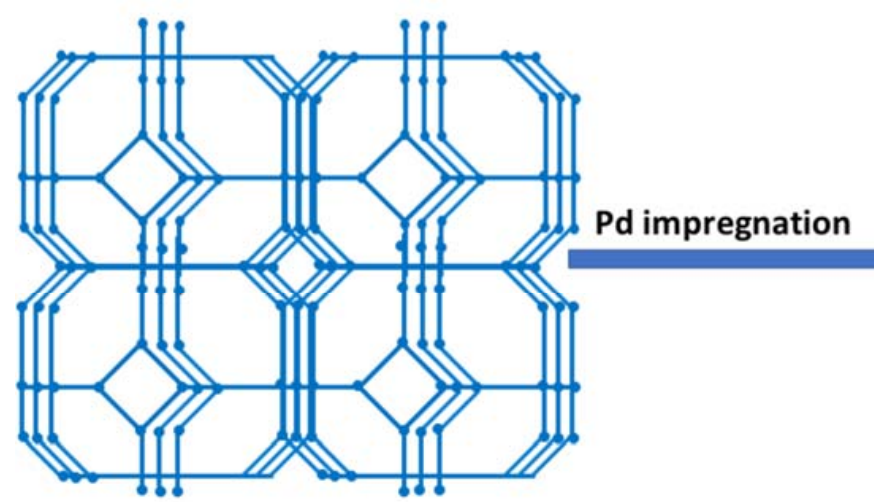

ZIF-8 structure

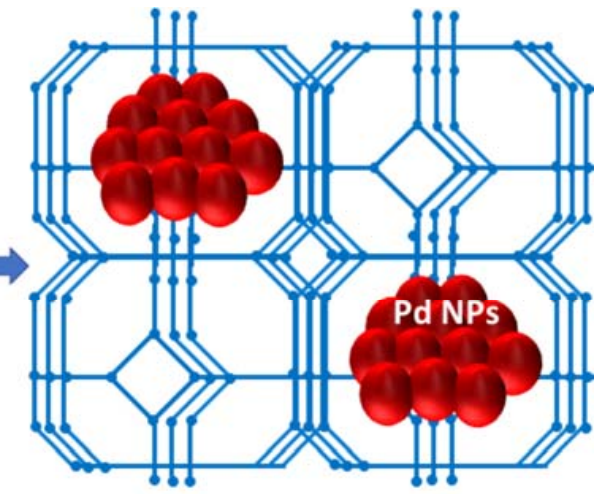

Pd/ZIF-8 catalyst

Figure 15. A graphical illustration of the Pd/zeolitic imidazolate (ZIF-8 catalyst) [88] (Adapted with permission from John Wiley and Sons).

Another interesting example was reported by Kozell et al. [89] who immobilised palladium nanoparticles on zirconium phosphate glycine diphosphonate nanosheets (ZPGly). The immobilization of palladium nanoparticles on ZPGly nanosheets provided a stable catalyst with high palladium content (up to 22 wt. \%). This Pd@ZPGly-15 catalyst proved to be highly efficient in catalysing Suzuki and Heck cross-couplings reactions. Surprisingly, the authors reported that their catalytic system operates as an efficient "heterogeneous" system, even though 3-5 ppm of palladium leached (Table 5). In addition, a "release and catch" mechanism was proposed in which soluble active palladium species are released from the solid Pd@ZPGly-15 catalyst during the oxidative addition of the halide and then re-deposited on the ZPGly support as a consequence of the reductive elimination step at the end of the reaction [89].

Table 5. Suzuki cross-coupling reaction between 4-bromobenzaldehyde and phenylboric acid catalysed by Pd@ZPGly-15 (palladium nanoparticles on zirconium phosphate glycine diphosphonate nanosheets) catalyst [89].

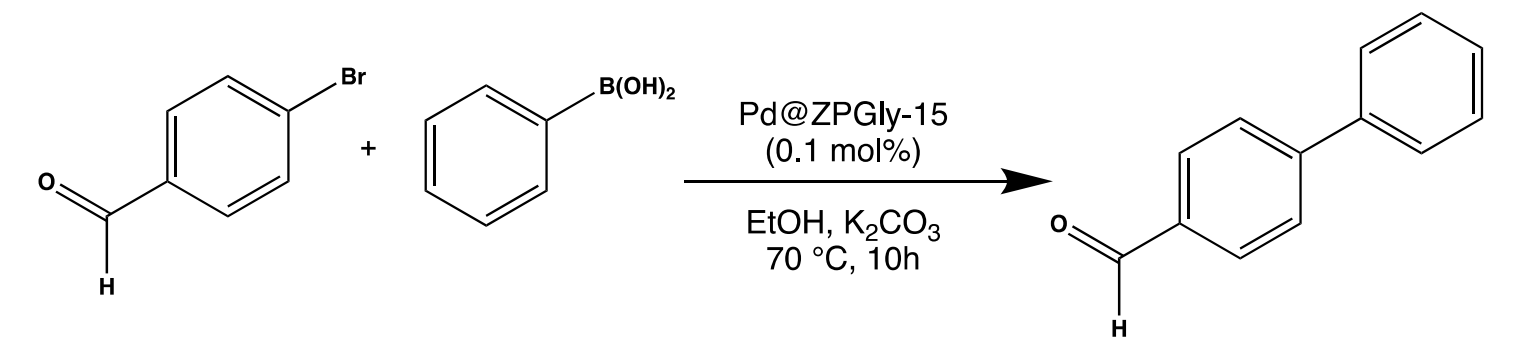

\begin{tabular}{ccc}
\hline Entry $^{\mathbf{a}}$ & Yield (\%) $^{\mathbf{b}}$ & Pd Leaching (ppm) \\
\hline Run 1 & 98 & 5 \\
Run 2 & 98 & 3 \\
Run 3 & 98 & 3 \\
\hline
\end{tabular}

${ }^{\mathrm{a}}$ Reaction conditions: 4-Bromobenzaldehyde (1.0 mmol), phenylboronic acid (1.2 mmol), $\mathrm{K}_{2} \mathrm{CO}_{3}(1.1 \mathrm{mmol})$, catalyst (0.1 mol \% Pd), ethanol (2.4 mL). ${ }^{\text {b }}$ GC (gas chromatography) yields. 
A magnetically separable version of a hybrid organic-inorganic support was recently reported by Omar and co-workers [90]. They supported palladium on magnetically separable organic-silica hybrid nanoparticles that were functionalized with ionic liquid groups (Figure 16). The presence of ionic liquid groups within the framework of the hybrid nanoparticles enhanced the stability of the palladium nanoparticles on the organic-silica nanoparticles. The resultant Pd/MNP@IL-SiO catalyst was efficiently applied in Heck and Suzuki cross-coupling reactions and it demonstrated high catalytic activity (Figure 16). The Pd/MNP@IL-SiO 2 catalyst was also easily separated from the reaction mixture by application of an external magnetic field and the catalyst could be recycled over five times without a significant loss in its catalytic activity. In conclusion, the authors envisaged that this and similar catalytic systems could pave a way for the desired bridging of homogeneous and heterogeneous catalysis.

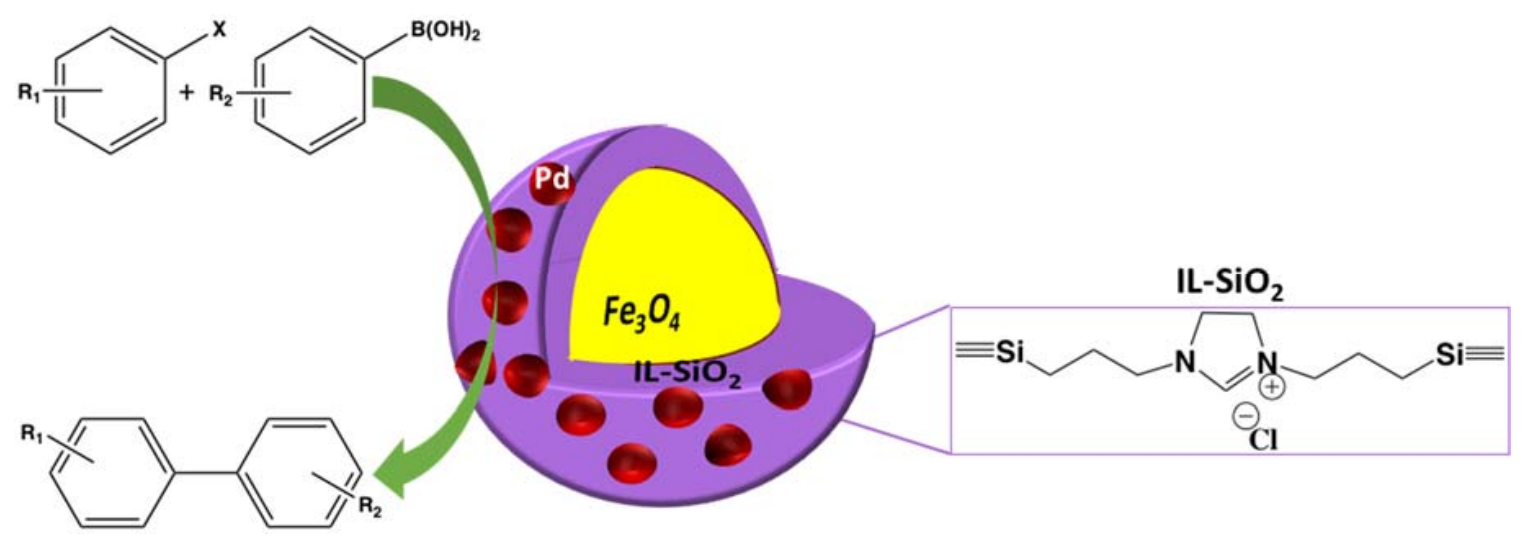

Figure 16. Suzuki cross-coupling reactions catalysed by the Pd/MNP@IL-SiO 2 (palladium nanoparticles on the organic-silica nanoparticles) catalyst [90] (Adapted with permission from American Chemical Society).

Another special type of hybrid organic-inorganic support was reported by Lin et al. who prepared a retrievable $\mathrm{Pd} / \mathrm{CMC} @ \mathrm{Ce}(\mathrm{OH})_{4}$ catalyst for Suzuki coupling-reactions [91]. In this system, $\mathrm{Ce}(\mathrm{OH})_{4}$ was coated with carboxymethylcellulose (CMC) to form a hybrid organic-inorganic $\mathrm{CMC} @ \mathrm{Ce}(\mathrm{OH})_{4}$ support (Scheme 9). Carboxymethylcellulose has a large number of inherent carboxylate (-COO-) and hydroxyl $(-\mathrm{OH})$ groups on its molecular chain. Thus, $\mathrm{CMC}$ is an excellent cation exchange agent, which makes it an excellent support for stabilization of palladium nanoparticles. While ceria has a unique ability of forming oxygen vacancies, that reduce $\mathrm{Ce}^{4+}$ to $\mathrm{Ce}^{3+}$ and create an excess of negative charge on its surface. The excess negative charge facilitates the coordination of palladium nanoparticles to the surface, as discussed earlier. These interactions have been shown to be crucial in preventing leaching and agglomeration of catalytic palladium nanoparticles. Scheme 9 shows an illustrative diagram of the conceptual mechanism of the Suzuki reaction catalyzed by $\mathrm{Pd}(0)-\mathrm{CMC} @ \mathrm{Ce}(\mathrm{OH})_{4}$. The $\mathrm{Ce}^{3+}$ on the surface of $\mathrm{Ce}(\mathrm{OH})_{4}$ enables the electronic charge transfer that produces a highly negatively charged palladium center. This then makes palladium a more electron rich site for facile oxidative addition of aryl halides, and thus allows catalysis to commence. 


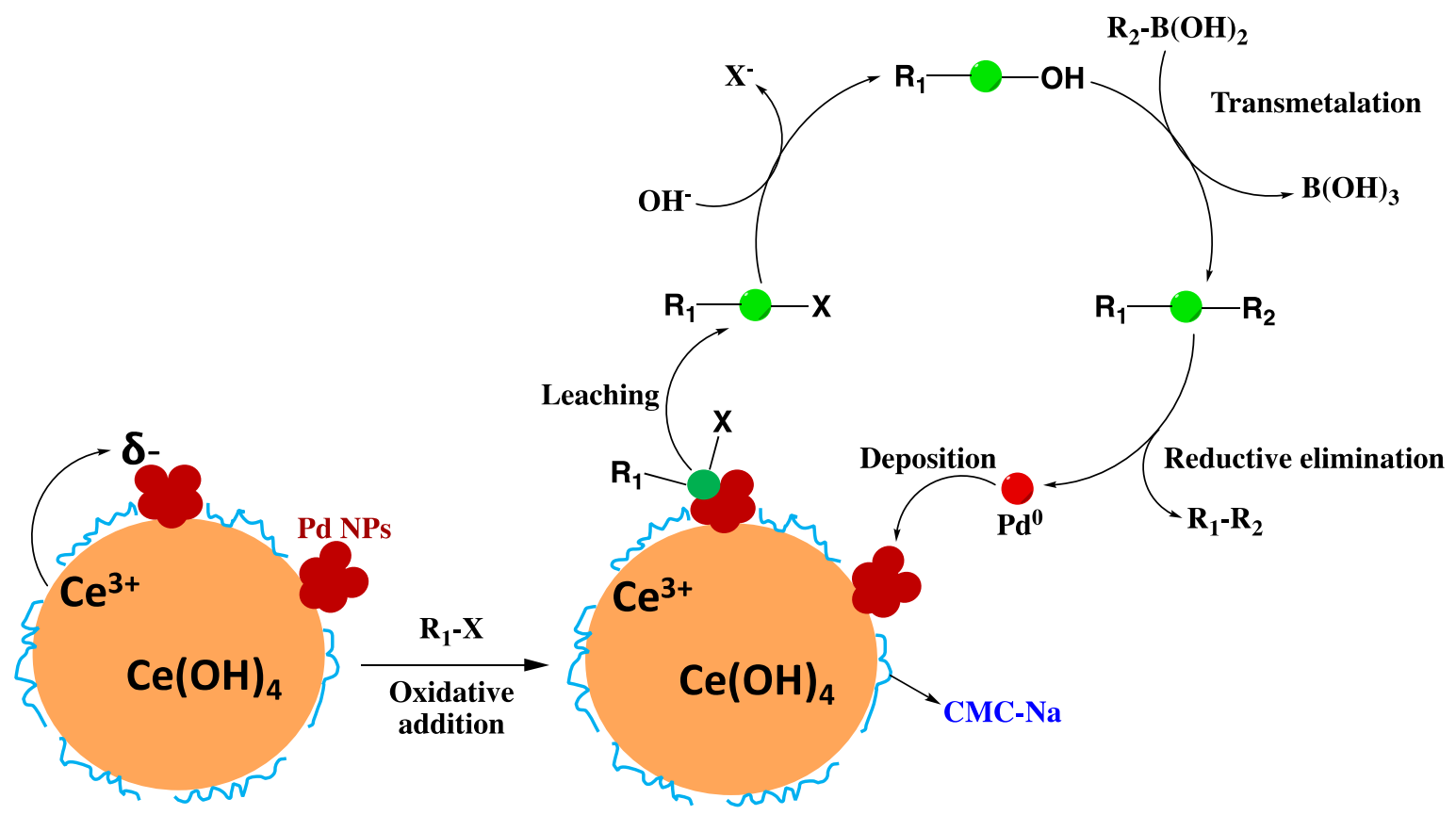

Scheme 9. Illustrative diagram of the conceptual mechanism of the Suzuki reaction catalyzed by $\mathrm{Pd} / \mathrm{CMC@Ce}(\mathrm{OH})_{4}[91]$ (Adapted with permission from Elsevier).

The Pd/CMC@Ce $(\mathrm{OH})_{4}$ catalyst was applied to the Suzuki cross-coupling reaction and good to excellent yields were obtained. It is believed that the activity of the catalyst was enhanced synergistically by the unique redox properties of $\mathrm{Ce}(\mathrm{OH})_{4}\left(\mathrm{Ce}^{3+} / \mathrm{Ce}^{4+}\right)$ and the coordination with the functional (carboxyl and hydroxyl) groups of the hybrid $\mathrm{CMC@Ce}(\mathrm{OH})_{4}$ support. Moreover, the catalyst could be easily separated by simple filtration and reused at least for five times without losing its activity. However, it was observed that $\mathrm{Pd}(0)$ species leached from the hybrid support during the reaction and were re-deposited onto the support at the end of the reaction. Therefore, the reaction mechanism is homogeneous in nature and the leached palladium species are the "true active species".

\section{Conclusions}

In conclusion, the literature survey shows that remarkable progress has been made regarding the activity and recyclability of heterogeneous palladium based catalytic systems for $\mathrm{C}-\mathrm{C}$ cross coupling reactions. However, thorough leaching and recyclability tests are still needed for most reported heterogeneous catalytic systems to unequivocally confirm that the palladium supported catalysts are responsible for the observed catalytic activity and not the leached material. Hence, at the moment it is hard to say what the nature of the true catalyst is, due to the dynamic nature of the reported catalytic systems for cross-coupling reactions.

Author Contributions: P.P.M. and Z.P.V. prepared this manuscript under the guidance and supervision of G.E.M.M. and H.B.F.

Funding: This research was funded by Mintek.

Acknowledgments: We would like to express our gratitude to Mintek and the Department of Science and Technology South Africa (Advanced Metals Initiative program) for financial support for our work in this area.

Conflicts of Interest: The authors declare no conflicts of interest.

\section{References}

1. Martinez, A.V.; Garcia, J.I.; Mayoral, J.A. An expedient synthesis of resveratrol through a highly recoverable palladium catalyst. Tetrahedron $2017,73,5581-5584$. [CrossRef] 
2. Biajoli, A.F.P.; Schwalm, C.S.; Limberger, J.; Claudino, T.S.; Monteiro, A.L. Recent progress in the use of Pd-catalyzed C-C cross-coupling reactions in the synthesis of pharmaceutical compounds. J. Braz. Chem. Soc. 2014, 25, 2186-2214. [CrossRef]

3. Barnard, B.C. Palladium-catalysed C-C coupling: Then and now. Platin. Met. Rev. 2008, 52, 38-45. [CrossRef]

4. Pagliaro, M.; Pandarus, V.; Ciriminna, R.; Béland, F.; Demma Carà, P. Heterogeneous versus homogeneous palladium catalysts for cross-coupling reactions. ChemCatChem 2012, 4, 432-445. [CrossRef]

5. Veerakumar, P.; Thanasekaran, P.; Lu, K.L.; Lin, K.C.; Rajagopal, S. Computational studies of versatile heterogeneous palladium-catalyzed Suzuki, Heck and Sonogashira coupling reactions. ACS Sustain. Chem. Eng. 2017, 5, 8475-8490. [CrossRef]

6. Yin, L.; Liebscher, J. Carbon-carbon coupling reactions catalyzed by heterogeneous palladium catalysts. Chem. Rev. 2007, 107, 133-173. [CrossRef] [PubMed]

7. Chinchilla, R.; Nájera, C. The Sonogashira Reaction: A Booming Methodology in Synthetic Organic Chemistry. Chem. Rev. 2007, 107, 874-922. [CrossRef] [PubMed]

8. Phan, N.T.S.; Van Der Sluys, M.; Jones, C.W. On the nature of the active species in palladium catalyzed Mizoroki-Heck and Suzuki-Miyaura couplings-Homogeneous or heterogeneous catalysis, a critical review. Adv. Synth. Catal. 2006, 348, 609-679. [CrossRef]

9. Ananikov, V.P.; Beletskaya, I.P. Toward the ideal catalyst: From atomic centers to a "cocktail" of catalysts. Organometallics 2012, 31, 1595-1604. [CrossRef]

10. Amoroso, F.; Colussi, S.; Del Zotto, A.; Llorca, J.; Trovarelli, A. Room-temperature Suzuki-Miyaura reaction catalyzed by Pd supported on rare earth oxides: Influence of the point of zero charge on the catalytic activity. Catal. Lett. 2013, 143, 547-554. [CrossRef]

11. Sanjaykumar, S.R.; Mukri, B.D.; Patil, S.; Madras, G.; Hegde, M.S. $\mathrm{Ce}_{0.98} \mathrm{Pd}_{0.02} \mathrm{O}_{2-\delta}$ : Recyclable, ligand free palladium(II) catalyst for Heck reaction. J. Chem. Sci. 2011, 123, 47-54. [CrossRef]

12. Khalili, D.; Banazadeh, A.R.; Etemadi-Davan, E. Palladium stabilized by amino-vinyl silica functionalized magnetic carbon nanotube: Application in Suzuki-Miyaura and Heck-Mizoroki coupling reactions. Catal. Lett. 2017, 147, 2674-2687. [CrossRef]

13. Veerakumar, P.; Thanasekaran, P.; Lu, K.L.; Liu, S.B.; Rajagopal, S. Functionalized silica matrices and palladium: A versatile heterogeneous catalyst for Suzuki, Heck, and Sonogashira reactions. ACS Sustain. Chem. Eng. 2017, 5, 6357-6376. [CrossRef]

14. Chorkendorff, I.B.; Niemantsverdriet, J.W. Introduction to Catalysis in Concepts of Modern Catalysis and Kinetics; WILEY-VCH Verlag GmbH \& Co. KGaA: Weinheim, Germany, 2003; pp. 1-22.

15. Astakhov, A.V.; Khazipov, O.V.; Chernenko, A.Y.; Pasyukov, D.V.; Kashin, A.S.; Gordeev, E.G.; Khrustalev, V.N.; Chernyshev, V.M.; Ananikov, V.P. A new mode of operation of Pd-NHC systems studied in a catalytic Mizoroki-Heck reaction. Organometallics 2017, 36, 1981-1992. [CrossRef]

16. Felpin, F.X.; Ayad, T.; Mitra, S. Pd/C: An old catalyst for new applications-Its use for the Suzuki-Miyaura reaction. Eur. J. Org. Chem. 2006, 2006, 2679-2690. [CrossRef]

17. Felpin, F.X. Ten years of adventures with Pd/C catalysts: From reductive processes to coupling reactions. Synlett 2014, 25, 1055-1067. [CrossRef]

18. Cini, E.; Petricci, E.; Taddei, M. Pd/C catalysis under microwave dielectric heating. Catalysts 2017, 7, 89. [CrossRef]

19. Wang, Y.; Mao, Y.; Lin, Q.; Yang, J. Preparation of nano Pd/C catalyst and catalysis for Heck reaction. Huagong Xinxing Cailiao 2014, 42, 132-135.

20. Zhou, X.Y.; Chen, X.; Wang, L.G. Recycled Pd/C catalyzed Heck reaction of 2-iodoanilines under ligand-free conditions. Synthesis 2017, 49, 5364-5370. [CrossRef]

21. Seki, M. Practical synthesis of multifunctional compounds through Pd/C-catalyzed coupling reactions. Yuki Gosei Kagaku Kyokaishi 2006, 64, 853-866. [CrossRef]

22. Schils, D.; Stappers, F.; Solberghe, G.; Van Heck, R.; Coppens, M.; Van den Heuvel, D.; Van der Donck, P.; Callewaert, T.; Meeussen, F.; De Bie, E.; et al. Ligandless Heck coupling between a halogenated aniline and acrylonitrile catalyzed by Pd/C: Development and optimization of an industrial-scale heck process for the production of a pharmaceutical intermediate. Org. Process Res. Dev. 2008, 12, 530-536. [CrossRef]

23. Dighe, M.G.; Lonkar, S.L.; Degani, M.S. Mechanistic insights into palladium leaching in novel Pd/C-catalyzed boron-Heck reaction of arylboronic acid. Synlett 2013, 24, 347-350. 
24. Freundlich, J.S.; Landis, H.E. An expeditious aqueous Suzuki-Miyaura method for the arylation of bromophenols. Tetrahedron Lett. 2006, 47, 4275-4279. [CrossRef]

25. Schmidt, B.; Riemer, M. Suzuki-Miyaura coupling of halophenols and phenol boronic acids: Systematic investigation of positional isomer effects and conclusions for the synthesis of phytoalexins from pyrinae. J. Org. Chem. 2014, 79, 4104-4118. [CrossRef] [PubMed]

26. Yuan, Y.Q.; Guo, S.R. Remarkably facile Heck reactions in aqueous two-phase system catalyzed by reusable $\mathrm{Pd} / \mathrm{C}$ under ligand-free conditions. Synth. Commun. 2012, 42, 1059-1069. [CrossRef]

27. Horikoshi, S.; Serpone, N. Role of microwaves in heterogeneous catalytic systems. Catal. Sci. Technol. 2014, 4, 1197-1210. [CrossRef]

28. Hattori, T.; Tsubone, A.; Sawama, Y.; Monguchi, Y.; Sajiki, H. Palladium on carbon-catalyzed Suzuki-Miyaura coupling reaction using an efficient and continuous flow system. Catalysts 2015, 5, 18-25. [CrossRef]

29. García-Suárez, E.J.; Lara, P.; García, A.B.; Ojeda, M.; Luque, R.; Philippot, K. Efficient and recyclable carbon-supported Pd nanocatalysts for the Suzuki-Miyaura reaction in aqueous-based media: Microwave vs conventional heating. Appl. Catal. A 2013, 468, 59-67. [CrossRef]

30. Giacalone, F.; Campisciano, V.; Calabrese, C.; La Parola, V.; Liotta, L.F.; Aprile, C.; Gruttadauria, M. Supported C60-IL-PdNPs as extremely active nanocatalysts for C-C cross-coupling reactions. J. Mater. Chem. 2016, 4, 17193-17206. [CrossRef]

31. Bowman, M.D.; Schmink, J.R.; McGowan, C.M.; Kormos, C.M.; Leadbeater, N.E. Scale-up of microwave-promoted reactions to the multigram level using a sealed-vessel microwave apparatus. Org. Process Res. Dev. 2008, 12, 1078-1088. [CrossRef]

32. Lakshminarayana, B.; Mahendar, L.; Ghosal, P.; Satyanarayana, G.; Subrahmanyam, C. Nano-sized recyclable $\mathrm{PdO}$ supported carbon nanostructures for Heck reaction: Influence of carbon materials. ChemistrySelect 2017, 2, 2700-2707. [CrossRef]

33. Jadhav, S.N.; Kumbhar, A.S.; Rode, C.V.; Salunkhe, R.S. Ligand-free Pd catalyzed cross-coupling reactions in an aqueous hydrotropic medium. Green Chem. 2016, 18, 1898-1911. [CrossRef]

34. Labulo, A.H.; Martincigh, B.S.; Omondi, B.; Nyamori, V.O. Advances in carbon nanotubes as efficacious supports for palladium-catalysed carbon-carbon cross-coupling reactions. J. Mater. Sci. 2017, 52, 9225-9248. [CrossRef]

35. Yang, L.; Cheng, G.; Xing, L.; Cheng, C.; Xia, L. Method for Activating Carbon Nanotube-Supported Palladium Nanoparticle Catalyst and Application Thereof. Patent CN106902817A, 30 June 2017.

36. Hosseini-Sarvari, M.; Razmi, Z.; Doroodmand, M.M. Palladium supported on zinc oxide nanoparticles: Synthesis, characterization, and application as heterogeneous catalyst for Mizoroki-Heck and Sonogashira reactions under ligand-free and air atmosphere conditions. Appl. Catal. A 2014, 475, 477-486. [CrossRef]

37. Del Zotto, A.; Colussi, S.; Trovarelli, A. Pd/REOs catalysts applied to the Suzuki-Miyaura coupling. A comparison of their catalytic performance and reusability. Inorg. Chim. Acta 2018, 470, 275-283. [CrossRef]

38. Köhler, K.; Heidenreich, R.G.; Soomro, S.S.; Pröckl, S.S. Supported palladium catalysts for Suzuki reactions: Structure-property relationships, optimized reaction protocol and control of palladium leaching. Adv. Synth. Catal. 2008, 350, 2930-2936. [CrossRef]

39. Gruttadauria, M.; Giacalone, F.; Noto, R. "Release and catch" catalytic systems. Green Chem. 2013, 15, 2608-2618. [CrossRef]

40. Adair, J.H.; Suvaci, E.; Sindel, J. Surface and Colloid Chemistry in Encyclopedia of Materials: Science and Technology, 2nd ed.; Cahn, R.W., Flemings, M.C., Ilschner, B., Kramer, E.J., Mahajan, S., Veyssière, P., Eds.; Elsevier: Oxford, UK, 2001; pp. 1-10.

41. Kosmulski, M. Compilation of PZCs/IEPs. In Surface Charging and Point of Zero Charge; Hubbard, A.T., Ed.; Taylor \& Francis Group: Boca Raton, FL, USA, 2009; pp. 101-524.

42. Del Zotto, A.; Zuccaccia, D. Metallic palladium, PdO, and palladium supported on metal oxides for the Suzuki-Miyaura cross-coupling reaction: A unified view of the process of formation of the catalytically active species in solution. Catal. Sci. Technol. 2017, 7, 3934-3951. [CrossRef]

43. Bera, P.; Hegde, M.S. Noble metal ions in $\mathrm{CeO}_{2}$ and $\mathrm{TiO}_{2}$ : Synthesis, structure and catalytic properties. RSC Adv. 2015, 5, 94949-94979. [CrossRef]

44. Cwele, T.; Mahadevaiah, N.; Singh, S.; Friedrich, H.B. Effect of $\mathrm{Cu}$ additives on the performance of a cobalt substituted ceria $\left(\mathrm{Ce}_{0.90} \mathrm{Co}_{0.10} \mathrm{O}_{2-\delta}\right)$ catalyst in total and preferential CO oxidation. Appl. Catal. B 2016, 182, 1-14. [CrossRef] 
45. Cwele, T.; Mahadevaiah, N.; Singh, S.; Friedrich, H.B.; Yadav, A.K.; Jha, S.N.; Bhattacharyya, D.; Sahoo, N.K. $\mathrm{CO}$ oxidation activity enhancement of $\mathrm{Ce}_{0.95} \mathrm{Cu}_{0.05} \mathrm{O}_{2-\delta}$ induced by Pd co-substitution. Catal. Sci. Technol. 2016, 6, 8104-8116. [CrossRef]

46. Gupta, A.; Waghmare, U.V.; Hegde, M.S. Correlation of oxygen storage capacity and structural distortion in transition-metal, noble-metal, and rare-earth-ion-substituted $\mathrm{CeO}_{2}$ from first principles calculation. Chem. Mater. 2010, 22, 5184-5198. [CrossRef]

47. Deshpande, P.A.; Hegde, M.S.; Madras, G. A mechanistic model for the water-gas shift reaction over noble metal substituted ceria. AIChE J. 2010, 56, 1315-1324. [CrossRef]

48. Hegde, M.S.; Madras, G.; Patil, K.C. Noble metal ionic catalysts. Acc. Chem. Res. 2009, 42, 704-712. [CrossRef] [PubMed]

49. Mpungose, P.P.; Sehloko, N.I.; Dasireddy, V.D.B.C.; Mahadevaiah, N.; Maguire, G.E.; Friedrich, H.B. $\mathrm{Pd}_{0.09} \mathrm{Ce}_{0.91} \mathrm{O}_{2-\delta}$ : A sustainable ionic solid-solution precatalyst for heterogeneous, ligand free Heck coupling reactions. Mol. Catal. 2017, 443, 60-68. [CrossRef]

50. Mpungose, P.P.; Sehloko, N.I.; Maguire, G.E.M.; Friedrich, H.B. PdCuCeO-TPAB: A new catalytic system for quasi-heterogeneous Suzuki-Miyaura cross-coupling reactions under ligand-free conditions in water. New J. Chem. 2017, 41, 13560-13566. [CrossRef]

51. Mpungose, P.P.; Sehloko, N.I.; Cwele, T.; Maguire, G.E.M.; Friedrich, H.B. $\mathrm{Pd}_{0.02} \mathrm{Ce}_{0.98} \mathrm{O}_{2-\delta}$ : A copper- and ligand-free quasi-heterogeneous catalyst for aquacatalytic Sonogashira cross-coupling reaction. J. South. Afr. Inst. Min. Metall. 2017, 117, 955-962. [CrossRef]

52. Burange, A.S.; Shukla, R.; Tyagi, A.K.; Gopinath, C.S. Palladium supported on fluorite structured redox $\mathrm{CeZrO}_{4-\delta}$ for heterogeneous suzuki coupling in water: A green protocol. ChemistrySelect 2016, 1, 2673-2681. [CrossRef]

53. Lichtenegger, G.J.; Maier, M.; Hackl, M.; Khinast, J.G.; Gössler, W.; Griesser, T.; Kumar, V.S.P.; Gruber-Woelfler, H.; Deshpande, P.A. Suzuki-Miyaura coupling reactions using novel metal oxide supported ionic palladium catalysts. J. Mol. Catal. A Chem. 2017, 426, 39-51. [CrossRef]

54. Karimi, B.; Mansouri, F.; Mirzaei, H.M. Recent applications of magnetically recoverable nanocatalysts in C-C and C-X coupling reactions. Chem CatChem 2015, 7, 1736-1789. [CrossRef]

55. Feng, C.; Liu, J.; Gui, J.; Liu, L. Application of magnetic nanoparticles supported Pd catalysts in C-C bond formation reactions. Yingyong Huaxue 2015, 32, 19-26.

56. Cheng, T.; Zhang, D.; Li, H.; Liu, G. Magnetically recoverable nanoparticles as efficient catalysts for organic transformations in aqueous medium. Green Chem. 2014, 16, 3401-3427. [CrossRef]

57. Baig, R.B.N.; Varma, R.S. Magnetically retrievable catalysts for organic synthesis. Chem. Commun. 2013, 49, 752-770. [CrossRef] [PubMed]

58. Rossi, L.M.; Garcia, M.A.S.; Vono, L.L.R. Recent advances in the development of magnetically recoverable metal nanoparticle catalysts. J. Braz. Chem. Soc. 2012, 23, 1959-1971. [CrossRef]

59. Xiao, C.; Yan, N.; Kou, Y. Quasi-homogeneous catalysis: Towards green and efficiency. Cuihua Xuebao 2009, 30, 753-764.

60. Mulahmetovic, E.; Hargaden, G.C. Recent advances in the development of magnetic catalysts for the Suzuki reaction. Rev. J. Chem. 2017, 7, 373-398. [CrossRef]

61. Elhampour, A.; Nemati, F. Palladium nanoparticles supported on modified hollow- $\mathrm{Fe}_{3} \mathrm{O}_{4} @ \mathrm{TiO}_{2}: \mathrm{Catalytic}$ activity in Heck and Sonogashira cross coupling reactions. Org. Prep. Proced. Int. 2017, 49, 443-458. [CrossRef]

62. Hudson, R.; Feng, Y.; Varma, R.S.; Moores, A. Bare magnetic nanoparticles: Sustainable synthesis and applications in catalytic organic transformations. Green Chem. 2014, 16, 4493-4505. [CrossRef]

63. Rossi, L.M.; Costa, N.J.S.; Silva, F.P.; Wojcieszak, R. Magnetic nanomaterials in catalysis: Advanced catalysts for magnetic separation and beyond. Green Chem. 2014, 16, 2906-2933. [CrossRef]

64. Nasrollahzadeh, M.; Mohammad Sajadi, S.; Rostami-Vartooni, A.; Khalaj, M. Green synthesis of $\mathrm{Pd} / \mathrm{Fe}_{3} \mathrm{O}_{4}$ nanoparticles using Euphorbia condylocarpa M. bieb root extract and their catalytic applications as magnetically recoverable and stable recyclable catalysts for the phosphine-free Sonogashira and Suzuki coupling reactions. J. Mol. Catal. A Chem. 2015, 396, 31-39. [CrossRef]

65. Xie, C.X.; Liu, Y.; Yu, S.T. Research progress of magnetic catalysts. Qingdao Keji Daxue Xuebao Ziran Kexueban 2015, 36, 237-244. 
66. Kumar, B.S.; Anbarasan, R.; Amali, A.J.; Pitchumani, K. Isolable C@ $\mathrm{Fe}_{3} \mathrm{O}_{4}$ nanospheres supported cubical Pd nanoparticles as reusable catalysts for Stille and Mizoroki-Heck coupling reactions. Tetrahedron Lett. 2017, 58, 3276-3282. [CrossRef]

67. Heidari, F.; Hekmati, M.; Veisi, H. Magnetically separable and recyclable $\mathrm{Fe}_{3} \mathrm{O}_{4} @ \mathrm{SiO}_{2} /$ isoniazide/Pd nanocatalyst for highly efficient synthesis of biaryls by Suzuki coupling reactions. J. Colloid Interface Sci. 2017, 501, 175-184. [CrossRef] [PubMed]

68. Collinson, J.M.; Wilton-Ely, J.D.E.T.; Diez-Gonzalez, S. Functionalised [(NHC)Pd(allyl)Cl] complexes: Synthesis, immobilisation and application in cross-coupling and dehalogenation reactions. Catal. Commun. 2016, 87, 78-81. [CrossRef]

69. Fareghi-Alamdari, R.; Saeedi, M.S.; Panahi, F. New bis(N-heterocyclic carbene) palladium complex immobilized on magnetic nanoparticles: As a magnetic reusable catalyst in Suzuki-Miyaura cross coupling reaction. Appl. Organomet. Chem. 2017, 31, e3870. [CrossRef]

70. Fan, H.; Qi, Z.; Sui, D.; Mao, F.; Chen, R.; Huang, J. Palladium nanoparticles in cross-linked polyaniline as highly efficient catalysts for Suzuki-Miyaura reactions. Chin. J. Catal. 2017, 38, 589-596. [CrossRef]

71. Taher, A.; Choudhary, M.; Nandi, D.; Siwal, S.; Mallick, K. Polymer-supported palladium: A hybrid system for multifunctional catalytic application. Appl. Organomet. Chem. 2017, 32, e3898. [CrossRef]

72. Ashouri, F.; Zare, M.; Bagherzadeh, M. The effect of framework functionality on the catalytic activation of supported Pd nanoparticles in the Mizoroki-Heck coupling reaction. C. R. Chim. 2017, 20, 107-115. [CrossRef]

73. Wang, C.A.; Li, Y.W.; Hou, X.M.; Han, Y.F.; Nie, K.; Zhang, J.P. N-Heterocyclic carbene-based microporous organic polymer supported palladium catalyst for carbon-carbon coupling reaction. ChemistrySelect 2016, 1, 1371-1376. [CrossRef]

74. Liu, X.; Zhao, X.; Lu, M. Novel polymer supported iminopyridylphosphine palladium (II) complexes: An efficient catalyst for Suzuki-Miyaura and Heck cross-coupling reactions. J. Organomet. Chem. 2014, 768, 23-27. [CrossRef]

75. Kodicherla, B.; Perumgani, C.P.; Keesara, S.; Mandapati, M.R. Polystyrene-supported palladium(II) N,N-dimethylethylenediamine complex: A recyclable catalyst for Suzuki-Miyaura cross-coupling reactions in water. Inorg. Chim. Acta 2014, 423, 95-100. [CrossRef]

76. Aravinda Reddy, P.; Babul Reddy, A.; Ramachandra Reddy, G.; Subbarami Reddy, N. Suzuki-Miyaura cross-coupling reaction of naphthyl triflate with indole boronic acids catalyzed by a recyclable polymer-supported n-heterocyclic carbene-palladium complex catalyst: Synthesis of naphthalene-linked bis-heterocycles. J. Heterocycl. Chem. 2013, 50, 1451-1456. [CrossRef]

77. Tamami, B.; Dodeji, F.N. Synthesis and application of modified polystyrene-supported palladium nanoparticles as a new heterogeneous catalyst for Heck and Suzuki cross-coupling reactions. J. Iran. Chem. Soc. 2012, 9, 841-850. [CrossRef]

78. Nemygina, N.A.; Nikoshvili, L.Z.; Bykov, A.V.; Sidorov, A.I.; Molchanov, V.P.; Sulman, M.G.; Tiamina, I.Y.; Stein, B.D.; Matveeva, V.G.; Sulman, E.M.; et al. Catalysts of Suzuki cross-coupling based on functionalized hyper-cross-linked polystyrene: Influence of precursor nature. Org. Process Res. Dev. 2016, 20, 1453-1460. [CrossRef]

79. Li, Y.; Xu, L.; Xu, B.; Mao, Z.; Xu, H.; Zhong, Y.; Zhang, L.; Wang, B.; Sui, X. Cellulose sponge supported palladium nanoparticles as recyclable cross-coupling catalysts. ACS Appl. Mater. Interfaces 2017, 9, 17155-17162. [CrossRef] [PubMed]

80. Rao, C.N.R.; Cheetham, A.K.; Thirumurugan, A. Hybrid inorganic-organic materials: A new family in condensed matter physics. J. Phys. Condens. Matter. 2008, 20, 1-21.

81. Wang, Y.; Dou, L.; Zhang, H. Nanosheet array-like palladium-catalysts Pdx/rGO@CoAl-LDH via lattice atomic-confined in situ reduction for highly efficient heck coupling reaction. ACS Appl. Mater. Interfaces 2017, 9, 38784-38795. [CrossRef] [PubMed]

82. Arsalani, N.; Akbari, A.; Amini, M.; Jabbari, E.; Gautam, S.; Chae, K.H. POSS-Based Covalent networks: Supporting and stabilizing pd for heck reaction in aqueous media. Catal. Lett. 2017, 147, 1086-1094. [CrossRef]

83. Woo, H.; Lee, K.; Park, K.H. Optimized dispersion and stability of hybrid $\mathrm{Fe}_{3} \mathrm{O}_{4} / \mathrm{Pd}$ catalysts in water for Suzuki coupling reactions. Impact of organic capping agents. ChemCatChem 2014, 6, 1635-1640. [CrossRef] 
84. Jing, X.; Sun, F.; Ren, H.; Tian, Y.; Guo, M.; Li, L.; Zhu, G. Targeted synthesis of micro-mesoporous hybrid material derived from octaphenylsilsesquioxane building units. Microporous Mesoporous Mater. 2013, 165, 92-98. [CrossRef]

85. Qu, K.; Wu, L.; Ren, J.; Qu, X. Natural DNA-modified graphene/Pd nanoparticles as highly active catalyst for formic acid electro-oxidation and for the Suzuki reaction. ACS Appl. Mater. Interfaces 2012, 4, 5001-5009. [CrossRef] [PubMed]

86. Yang, H.; Ma, Z.; Qing, Y.; Xie, G.; Gao, J.; Zhang, L.; Gao, J.; Du, L. A periodic mesoporous hybrid material with a built-in palladium complex: An efficient catalyst for the Suzuki coupling and alcohol oxidation. Appl. Catal. A 2010, 382, 312-321. [CrossRef]

87. Wang, B.; Gu, Y.L.; Yang, L.M.; Suo, J.S. Organic/inorganic hybrid materials-supported metal complex catalysts: New applications of sol-gel technology. Fenzi Cuihua 2003, 17, 468-480.

88. Shaikh, M.N.; Abdul Aziz, M.; Helal, A.; Kalanthoden, A.N.; Yamani, Z.H. PdNPs@ZIF-8 micro-nanostructured catalyst of regioselective Mizoriki-Heck olefination. ChemistrySelect 2017, 2, 9052-9057. [CrossRef]

89. Kozell, V.; Giannoni, T.; Nocchetti, M.; Vivani, R.; Piermatti, O.; Vaccaro, L. Immobilized palladium nanoparticles on zirconium carboxy-aminophosphonates nanosheets as an efficient recoverable heterogeneous catalyst for suzuki-miyaura and heck coupling. Catalysts 2017, 7, 186. [CrossRef]

90. Omar, S.; Abu-Reziq, R. Palladium nanoparticles supported on magnetic organic-silica hybrid nanoparticles. J. Phys. Chem. C 2014, 118, 30045-30056. [CrossRef]

91. Lin, B.; Liu, X.; Zhang, Z.; Chen, Y.; Liao, X.; Li, Y. Pd(0)-CMC@Ce(OH) $)_{4}$ organic/inorganic hybrid as highly active catalyst for the Suzuki-Miyaura reaction. J. Colloid Interface Sci. 2017, 497, 134-143. [CrossRef] [PubMed]

(C) 2018 by the authors. Licensee MDPI, Basel, Switzerland. This article is an open access article distributed under the terms and conditions of the Creative Commons Attribution (CC BY) license (http://creativecommons.org/licenses/by/4.0/). 